\title{
Immobilized Platinum Hydride Species as Catalysts for Olefin Isomerizations and Enyne Cycloisomerizations
}

Sarah Maier, ${ }^{1}$ Steve P. Cronin, ${ }^{1}$ Manh-Anh Vu Dinh, ${ }^{1}$ Zheng Li, ${ }^{1}$ Michael Dyballa, ${ }^{1}$ Michal Nowakowski, ${ }^{2}$ Matthias Bauer, ${ }^{2}$ Deven P. Estes*1

1)Institute of Technical Chemistry, University of Stuttgart, Pfaffenwaldring 55, D-70569, Stuttgart, Germany. 2)Department of Chemistry, University of Paderborn, Warburger Straße 100, D-33098, Paderborn, Germany

\section{Supporting Information}

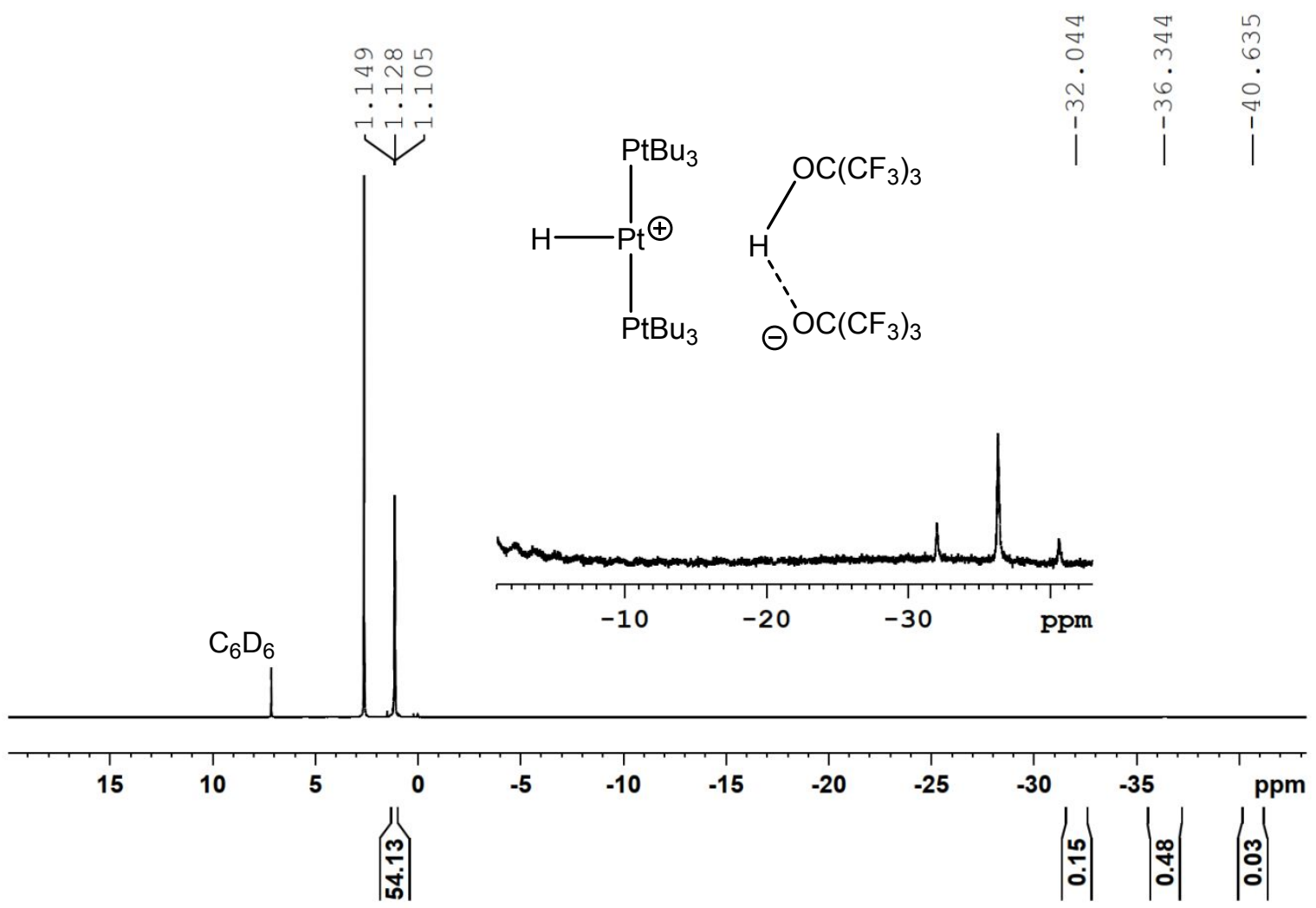

Figure S1. ${ }^{1} \mathrm{H}$ NMR of compound 3. (peak at ca. $2.6 \mathrm{ppm}$ is due to the $\mathrm{OH}$ of the excess $\mathbf{2 d}$ in the NMR tube, needed to fully convert the complex). 


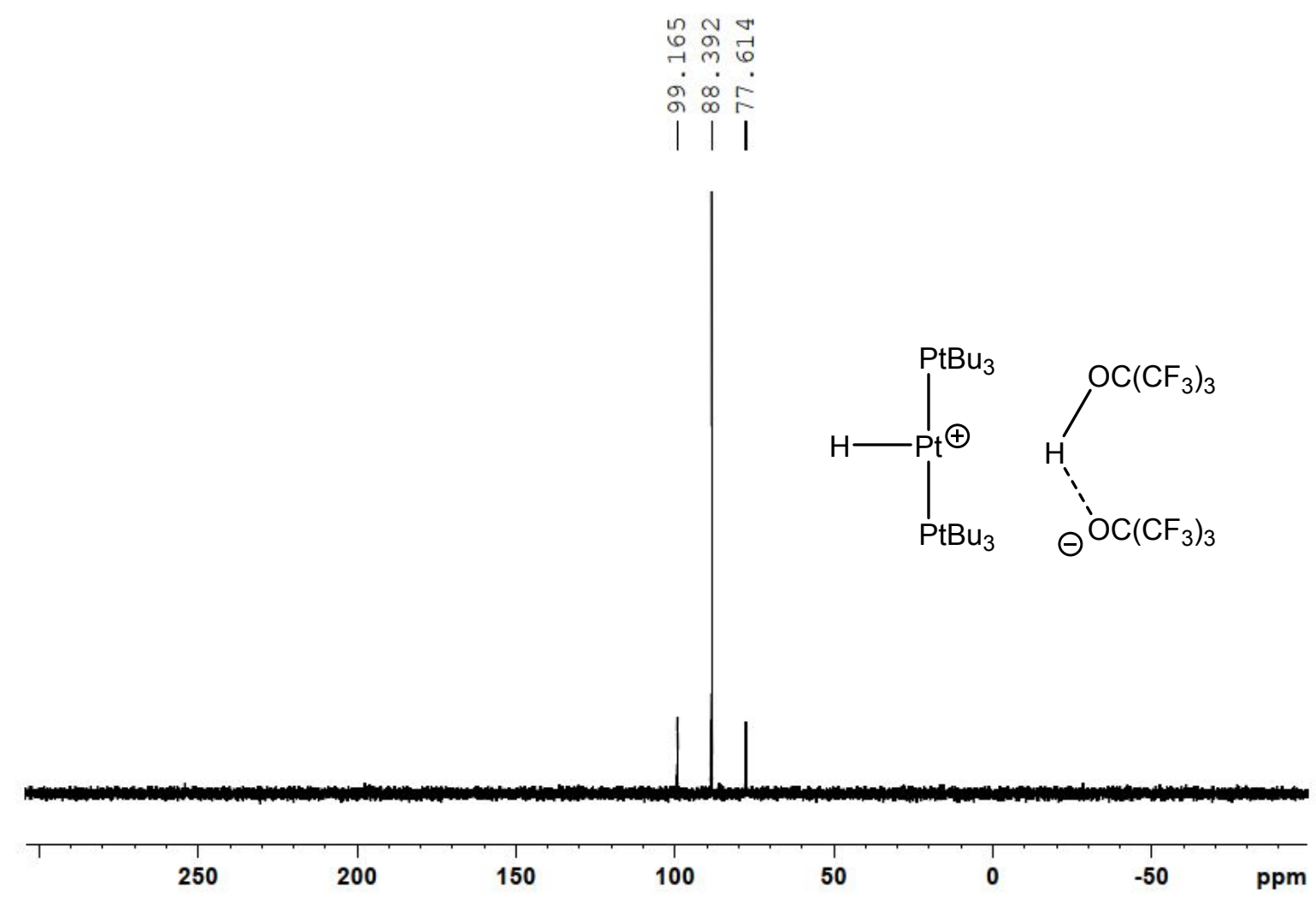

Figure S2. ${ }^{31} \mathrm{P}\left\{{ }^{1} \mathrm{H}\right\}$ NMR spectrum of compound 3 .

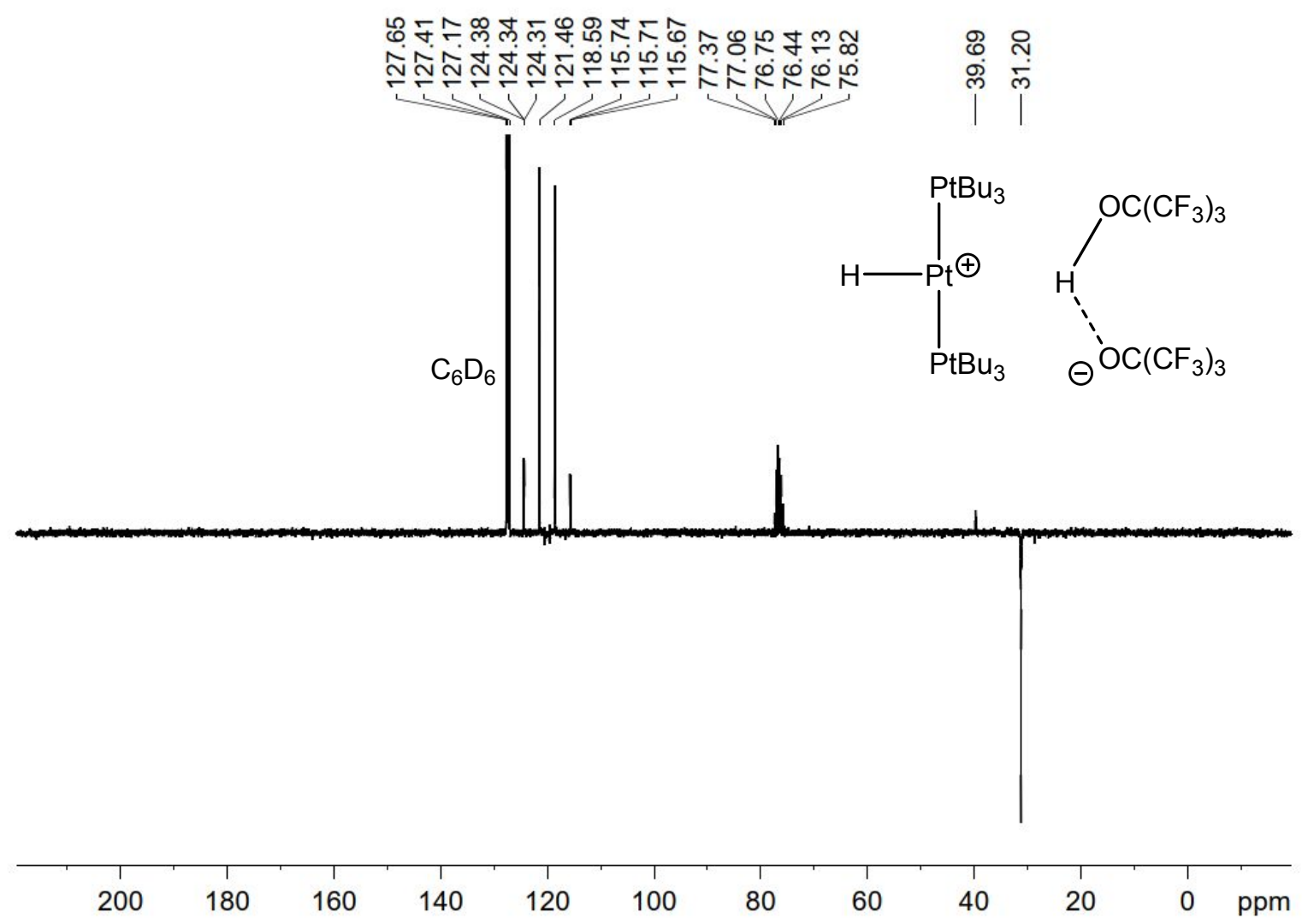

Figure S3. ${ }^{13} \mathrm{C}$ APT NMR Spectrum of compound 3 . 


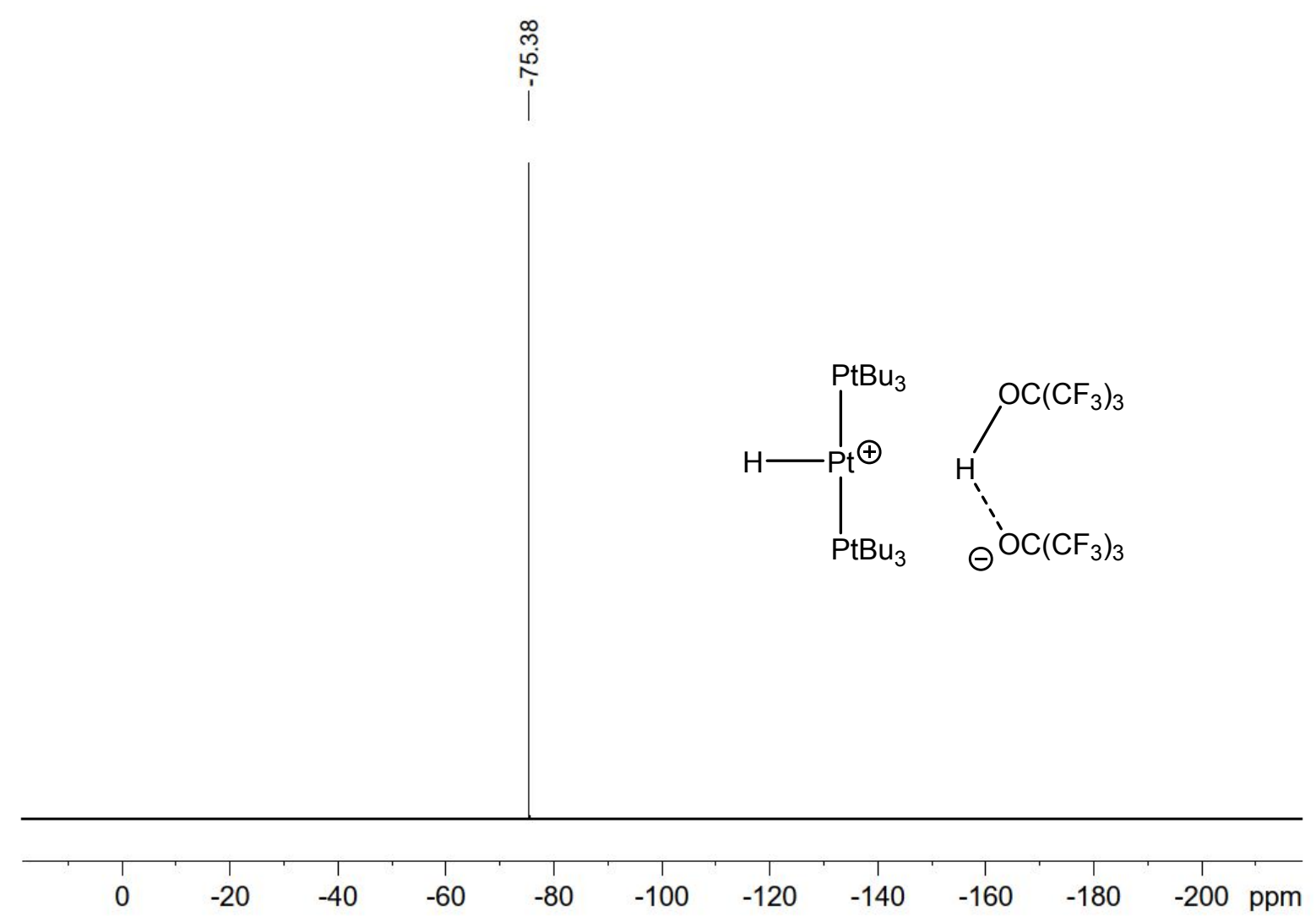

Figure S4. ${ }^{19} \mathrm{~F}$ NMR Spectrum of compound 3.

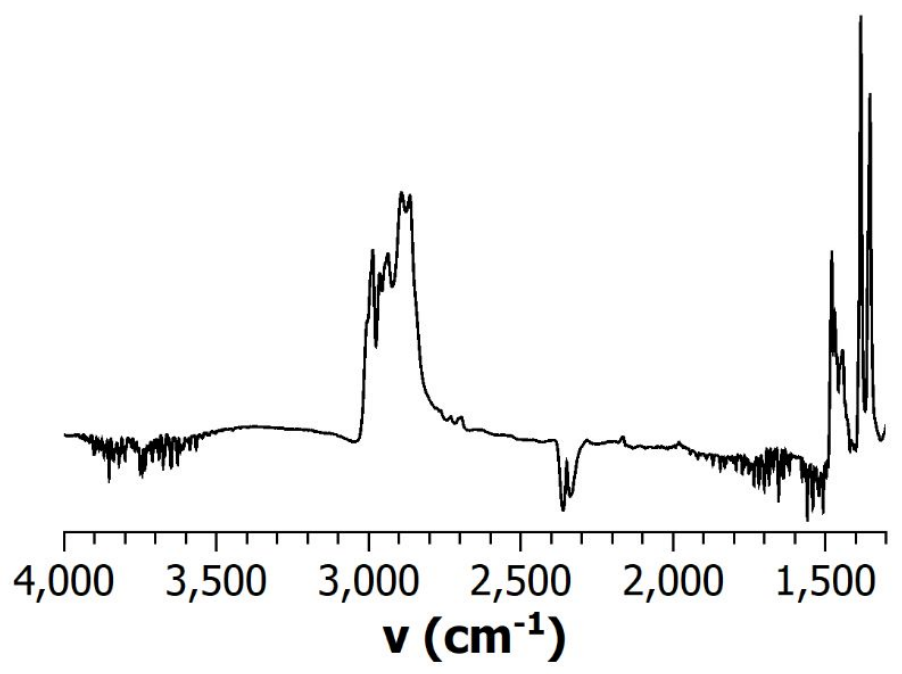

Figure S5. ATR IR of compound 3. 


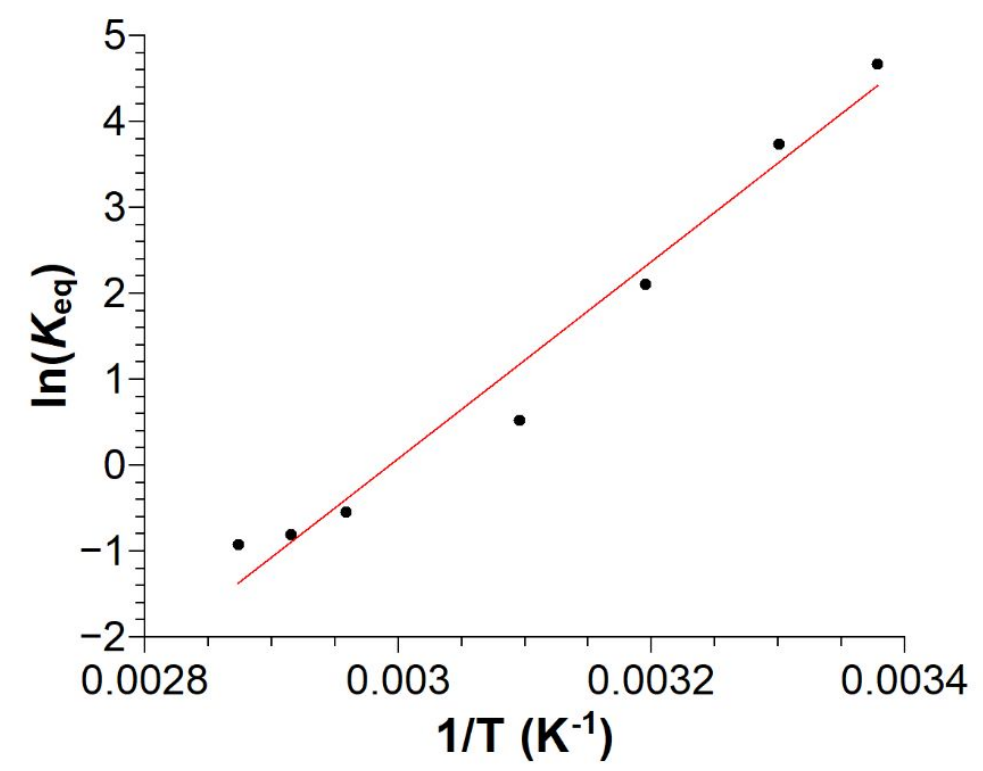

Figure S6. Temperature dependence of $K_{\text {eq }}$ in the range $23-75^{\circ} \mathrm{C}$. 

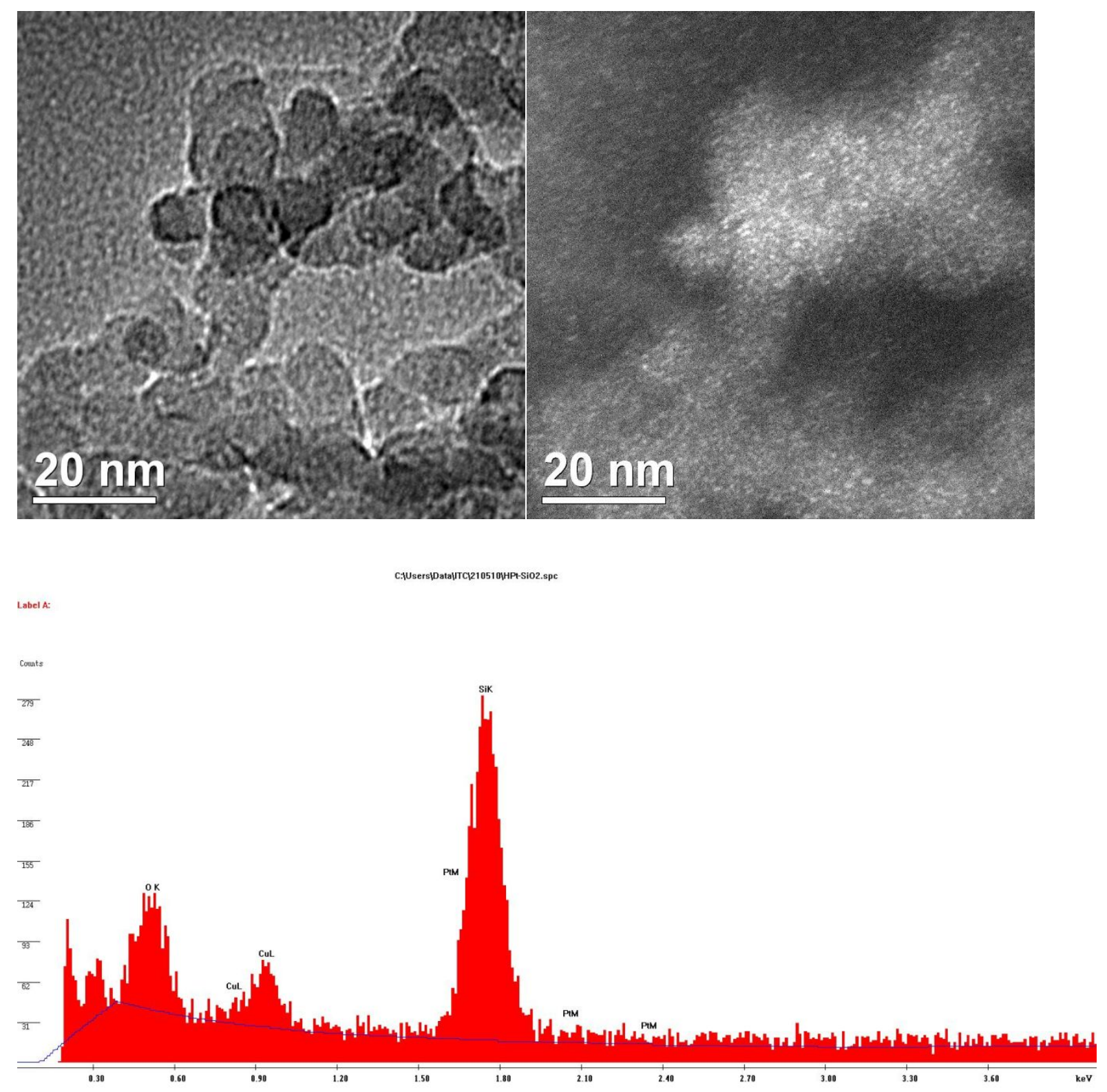

Figure S7. Bright field (top left) and dark field (top right) TEM and EDX (bottom) of catalyst $\mathbf{4 a}$. 

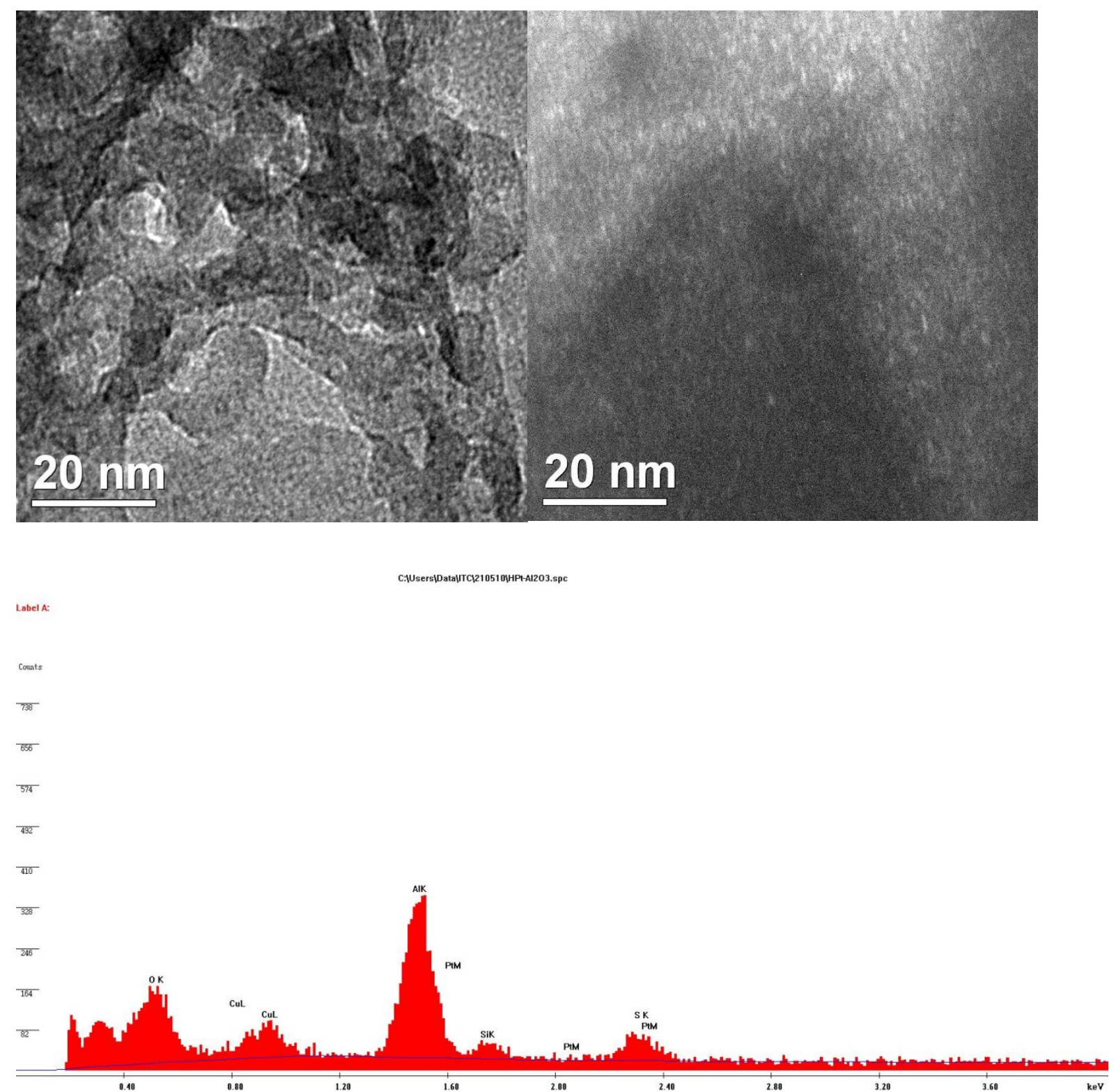

Figure S8. Bright field (top left) and dark field (top right) TEM and EDX spectrum (bottom) of catalyst $\mathbf{4 b}$. 

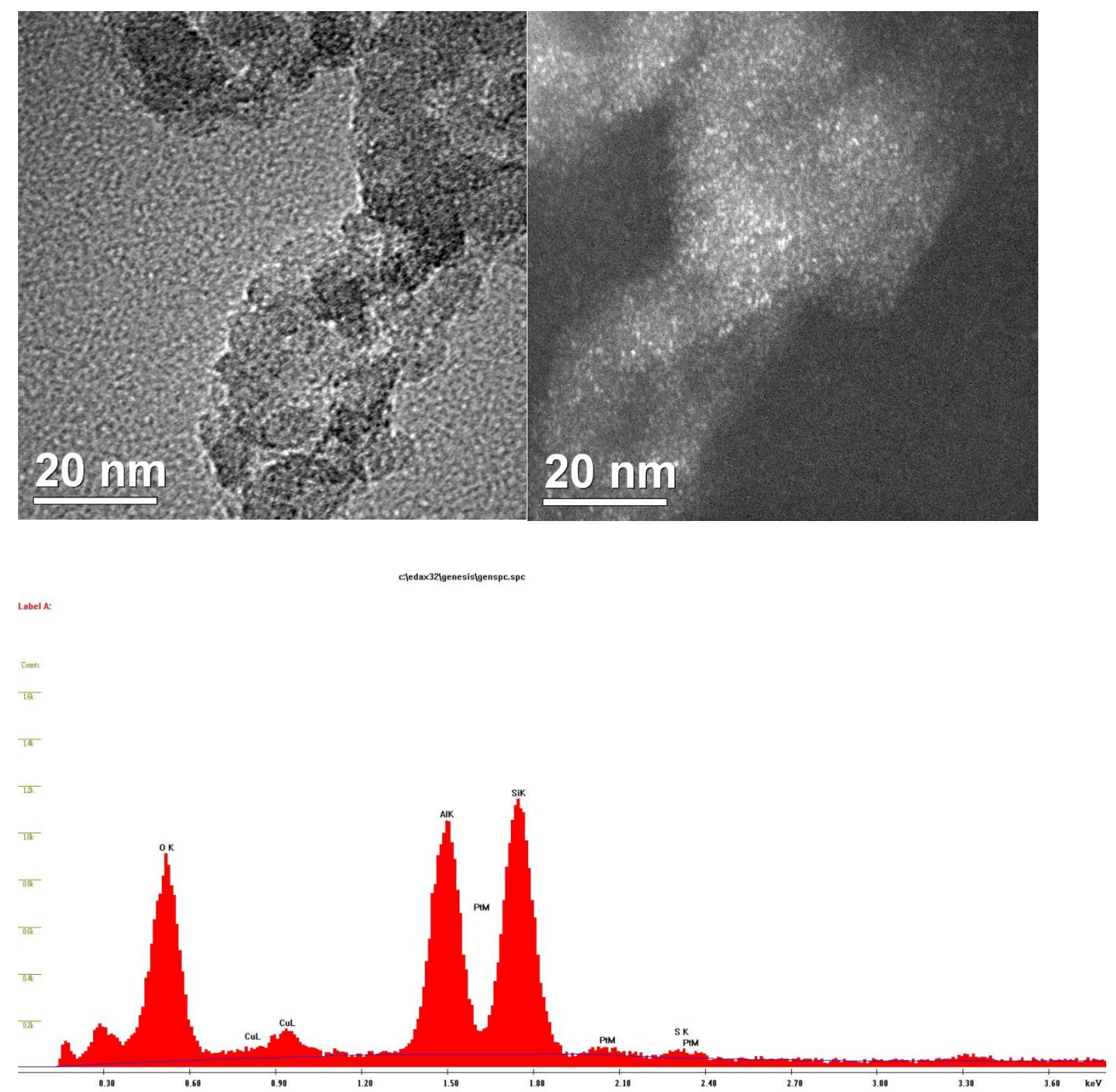

Figure S9. Bright field (top left) and dark field (top right) TEM and EDX spectrum of catalyst 4c. 


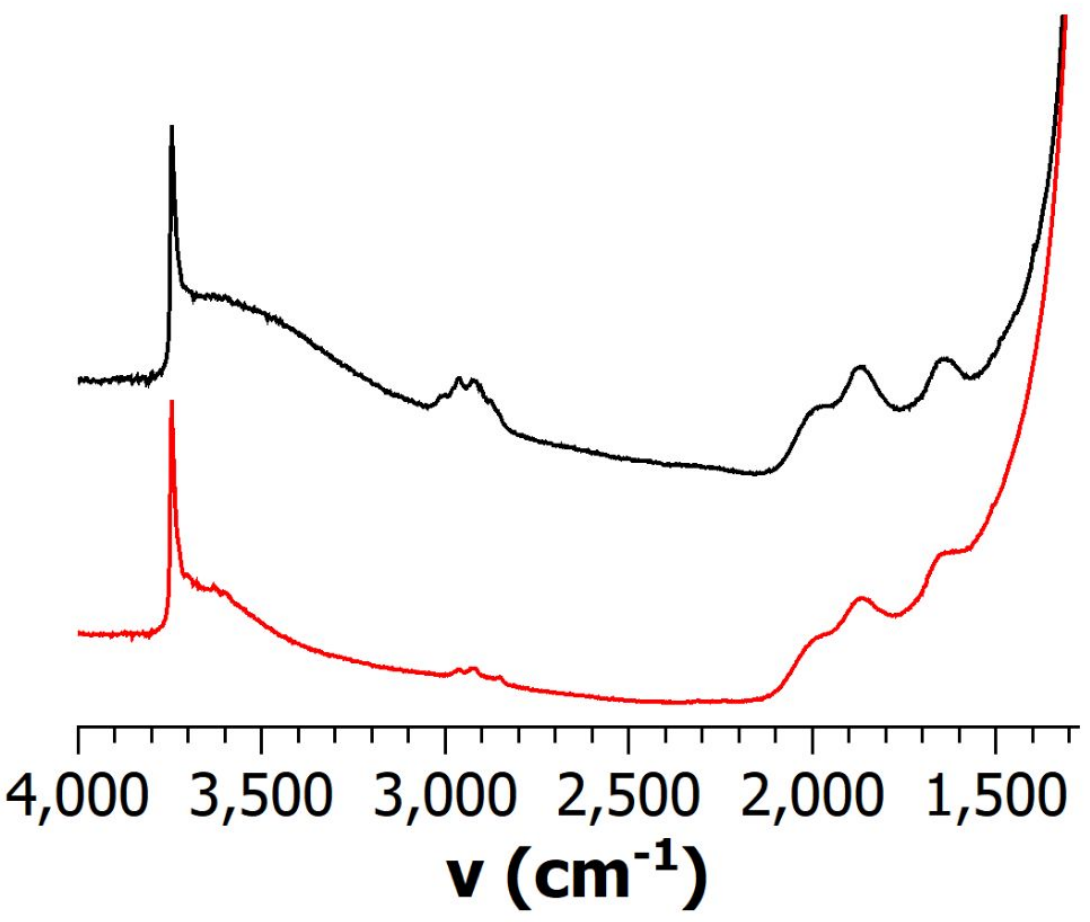

Figure S10. IR spectrum of catalyst 4 a (black) and $\mathrm{SiO}_{2}$ (red).

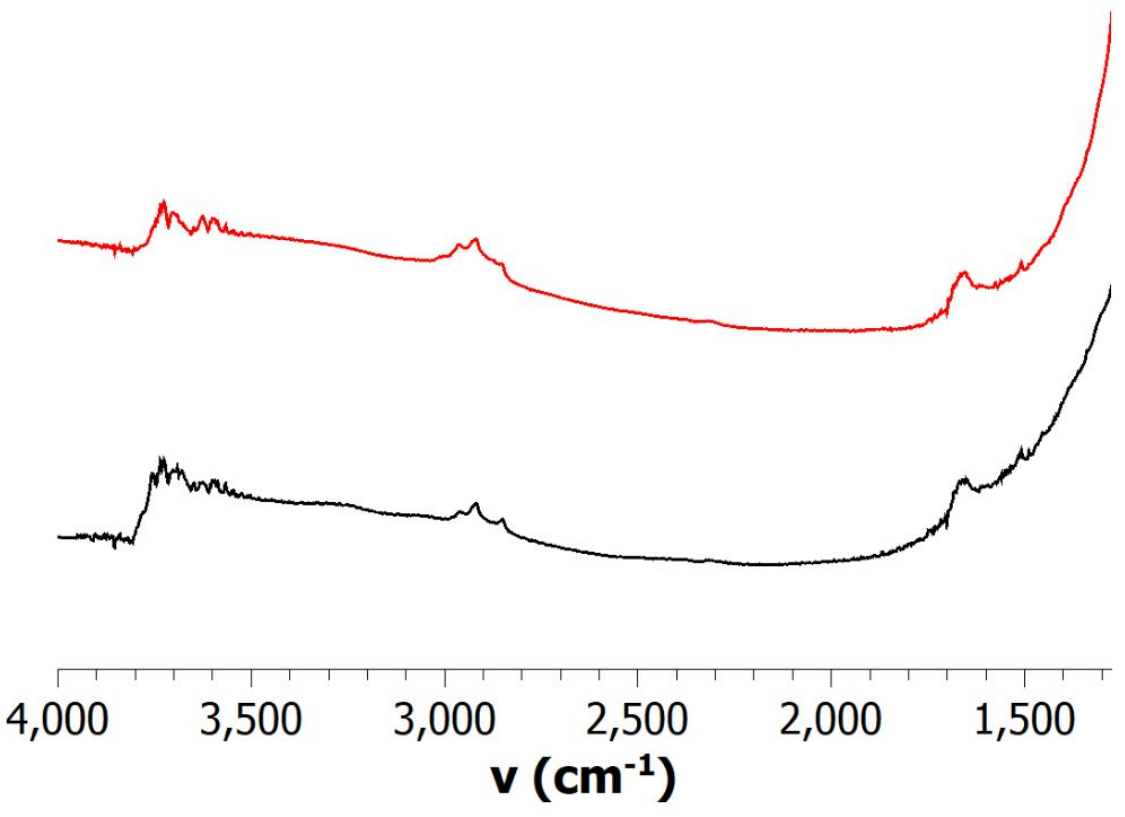

Figure S11. IR spectrum of $\mathrm{Al}_{2} \mathrm{O}_{3}$ (black) and catalyst $\mathbf{4 b}$ (red). 


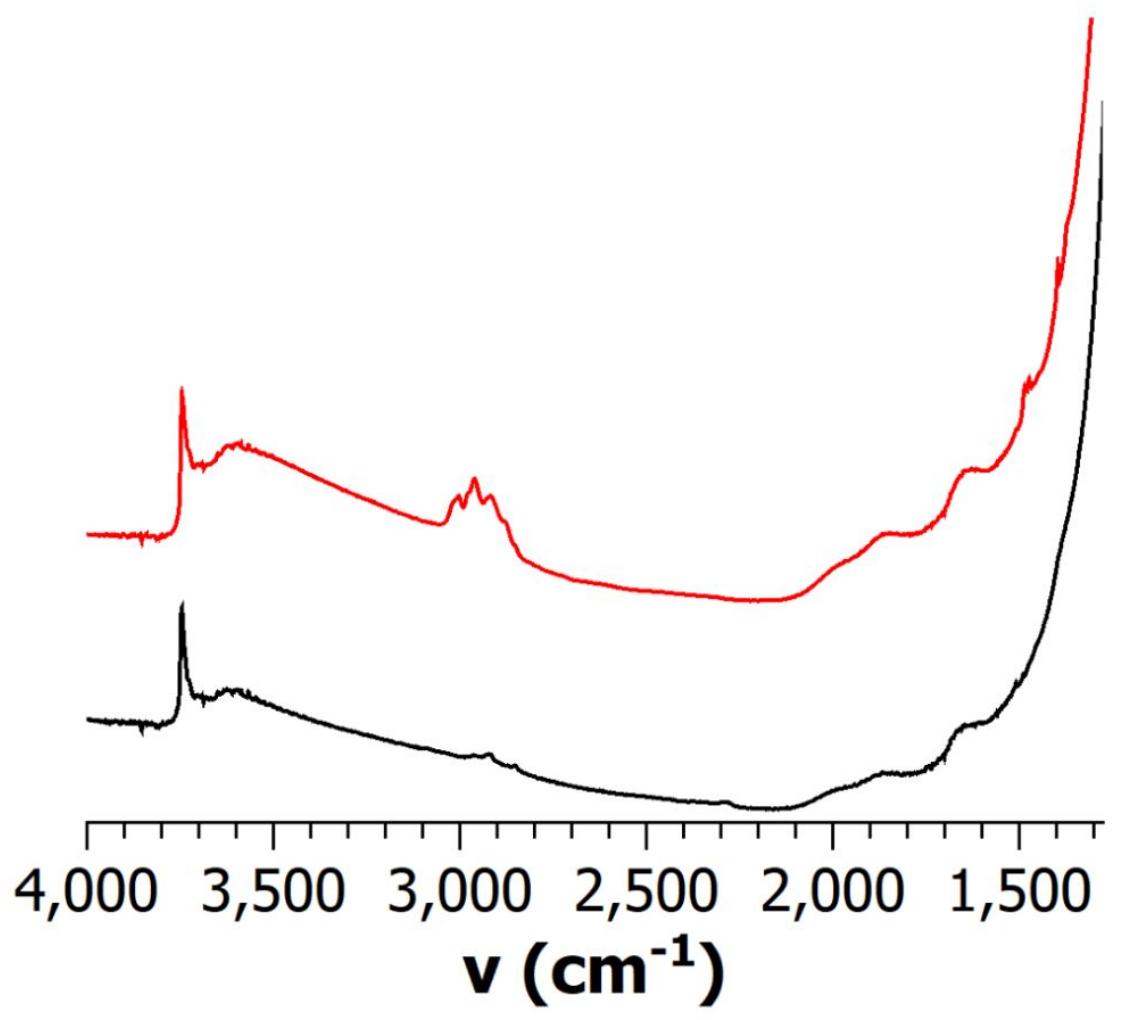

Figure S12. IR spectrum of $\mathrm{SiO}_{2}-\mathrm{Al}_{2} \mathrm{O}_{3}$ (black) and catalyst 4c (red). 


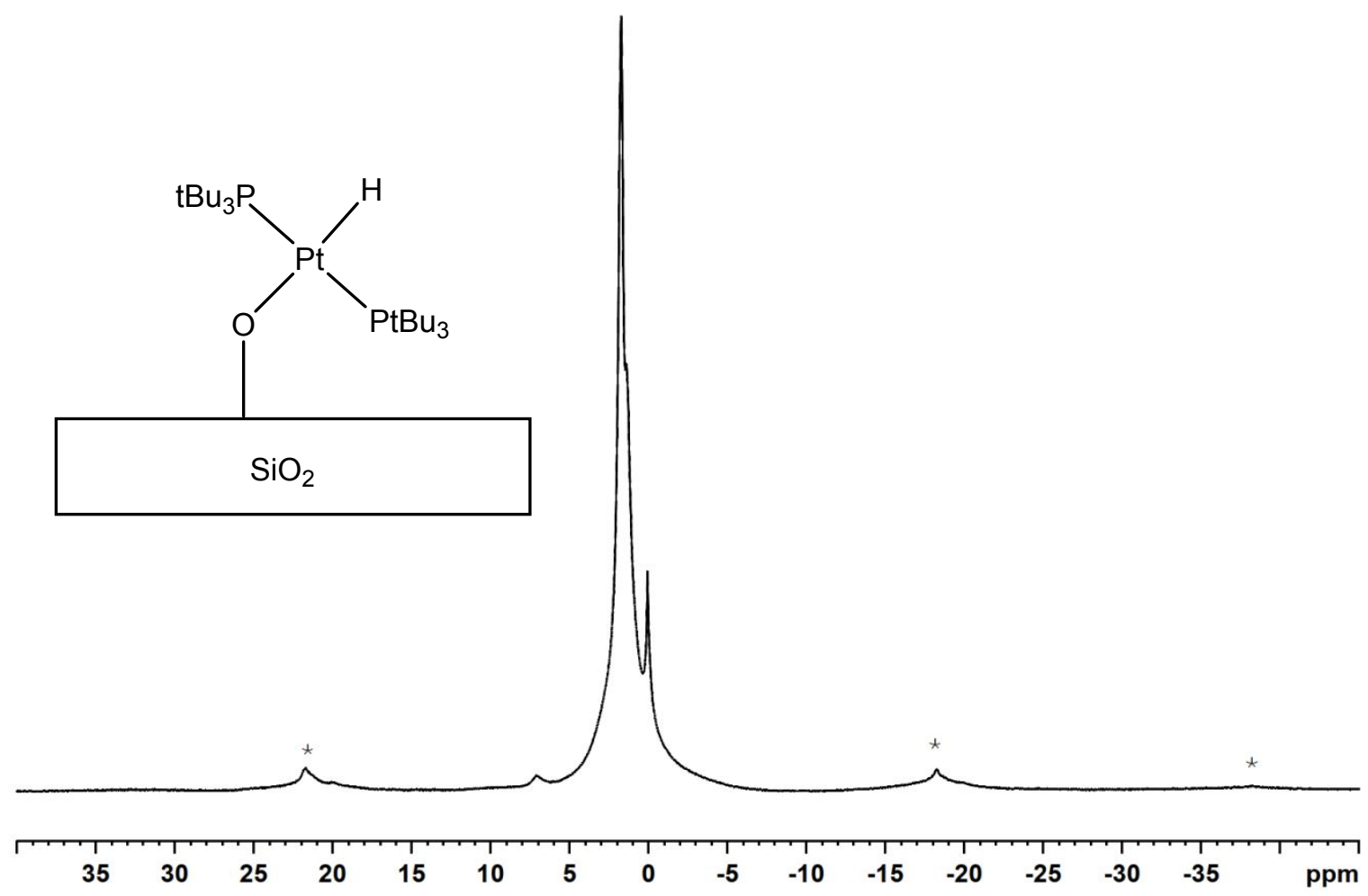

Figure S13. ${ }^{1} \mathrm{H}$ MAS NMR spectrum of catalyst $4 a$. ( ${ }^{*}$ are spinning side bands).

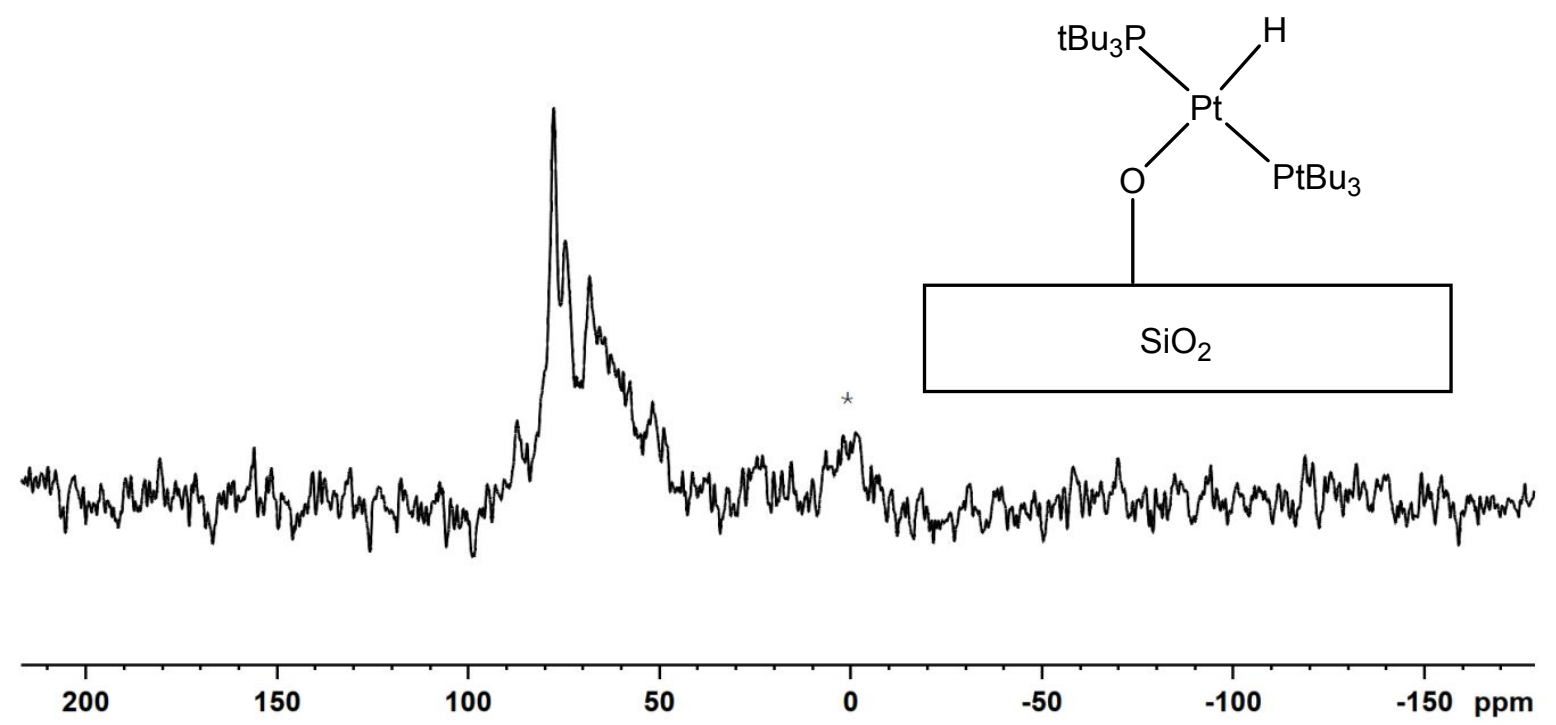

Figure S14. ${ }^{31} \mathrm{P}$ CPMAS NMR spectrum of catalyst $4 \mathrm{a}$ ( ${ }^{*}$ are spinning side bands). 


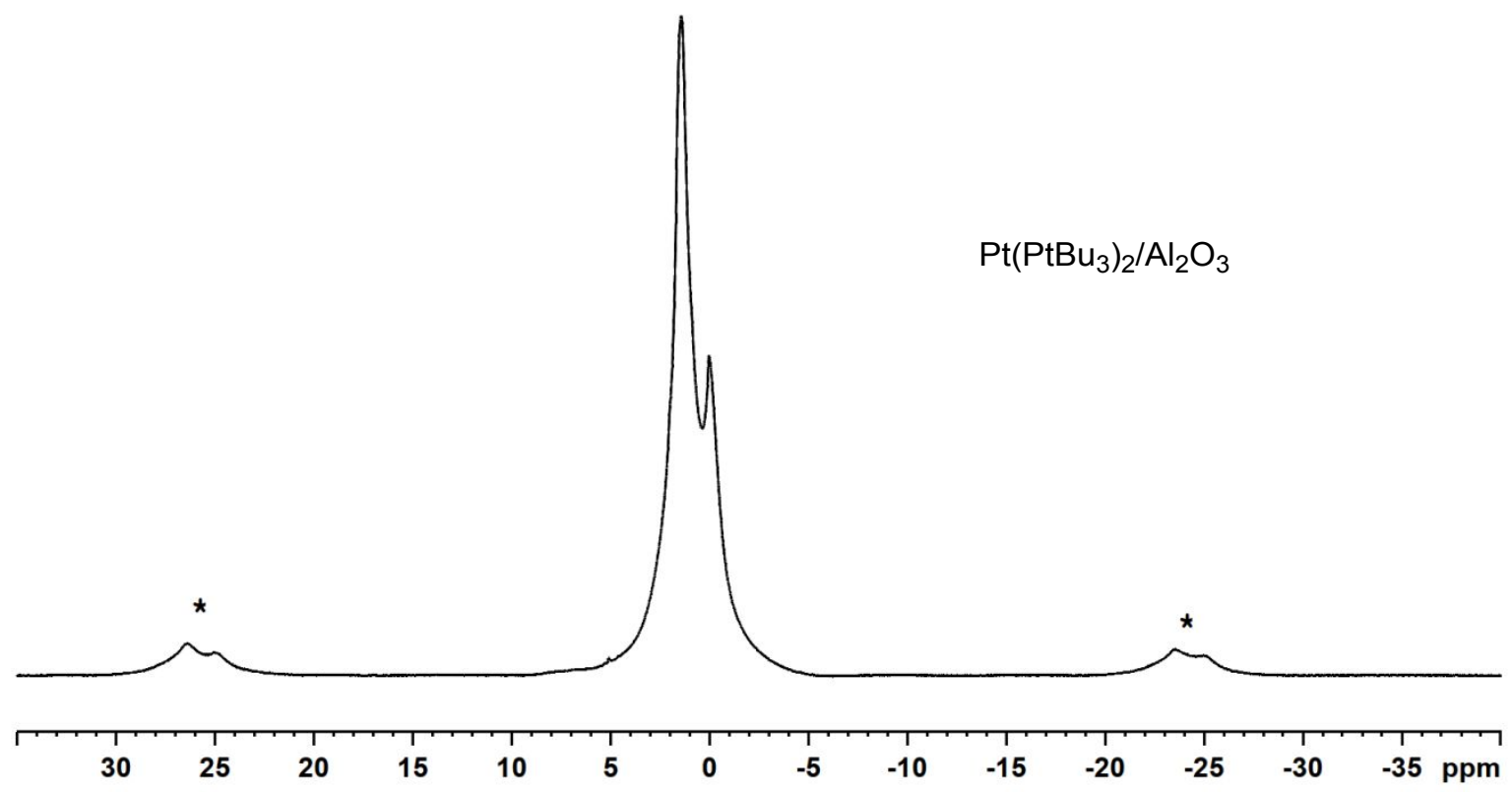

Figure S15. ${ }^{1} \mathrm{H}$ MASNMR spectrum of catalyst $\mathbf{4 b}$ ( ${ }^{*}$ are spinning side bands).

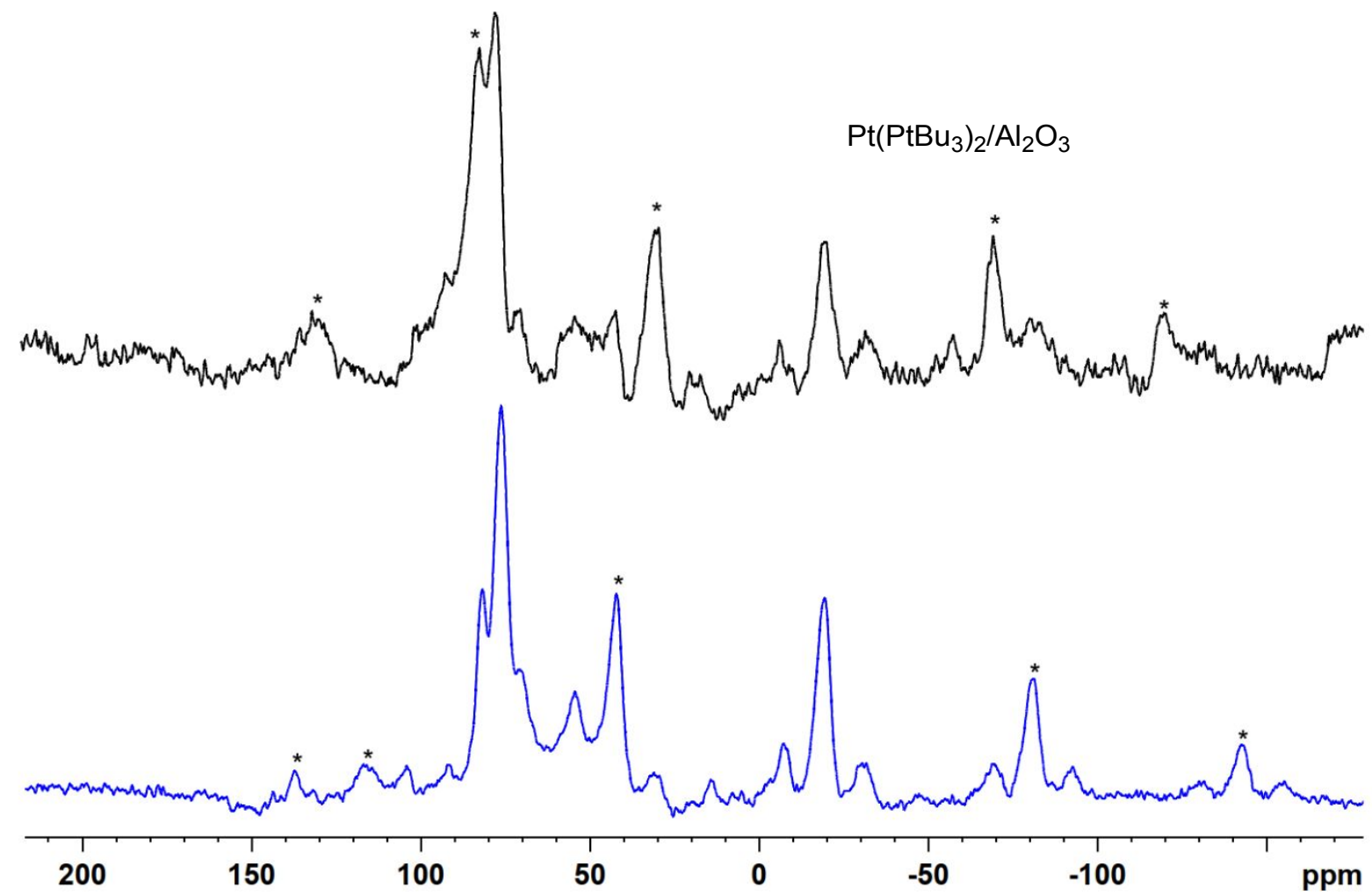

Figure S16. ${ }^{31} \mathrm{P}$ CPMAS NMR Spectrum of catalyst $\mathbf{4 b}$ at $8 \mathrm{kHz}$ (black) and $10 \mathrm{kHz}$ (blue) MAS frequency ( ${ }^{*}$ are spinning side bands). 


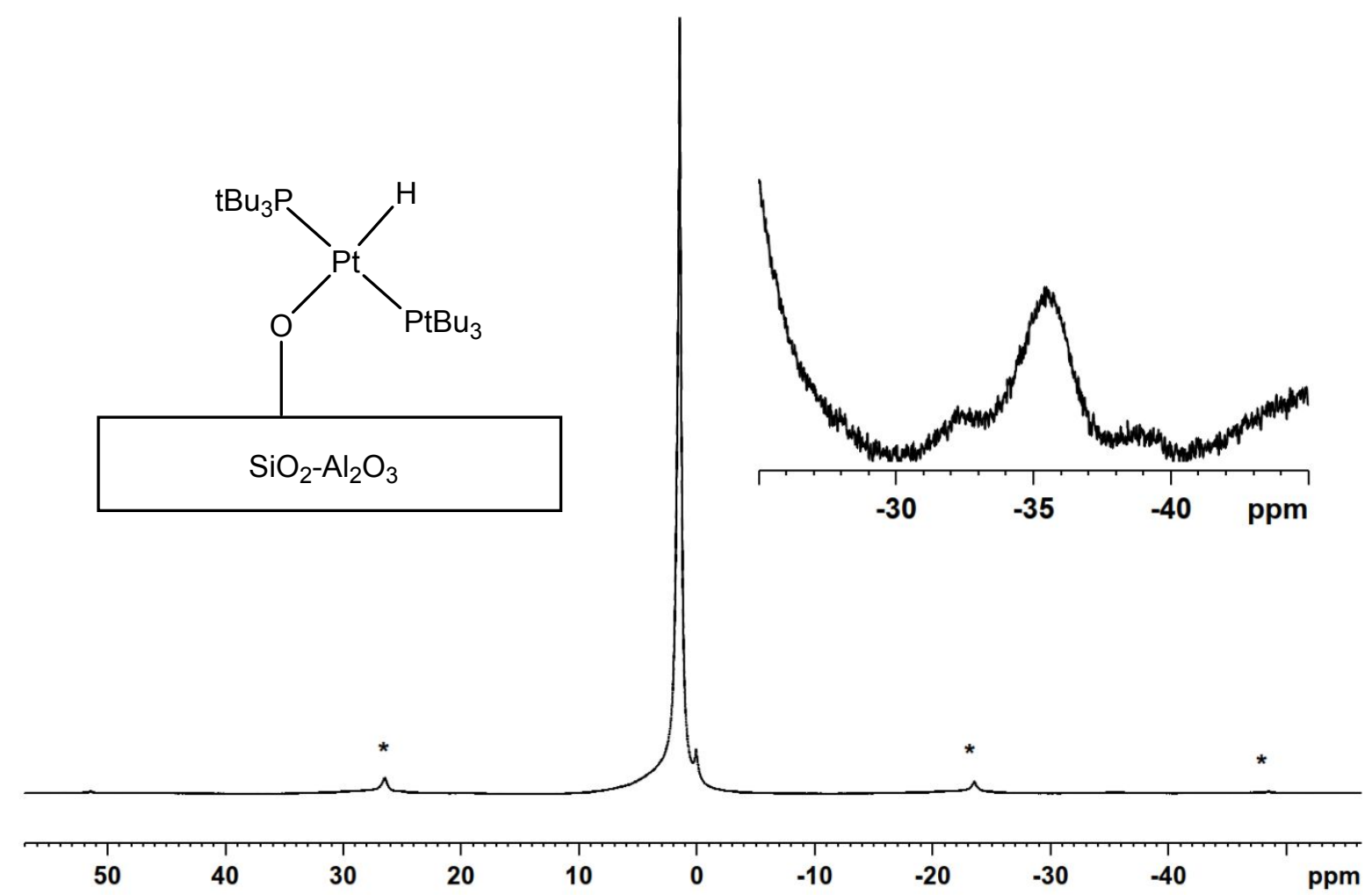

Figure S17. ${ }^{1} \mathrm{H}$ MAS NMR spectrum of catalyst $4 \mathrm{c}$ ( ${ }^{*}$ are spinning side bands).

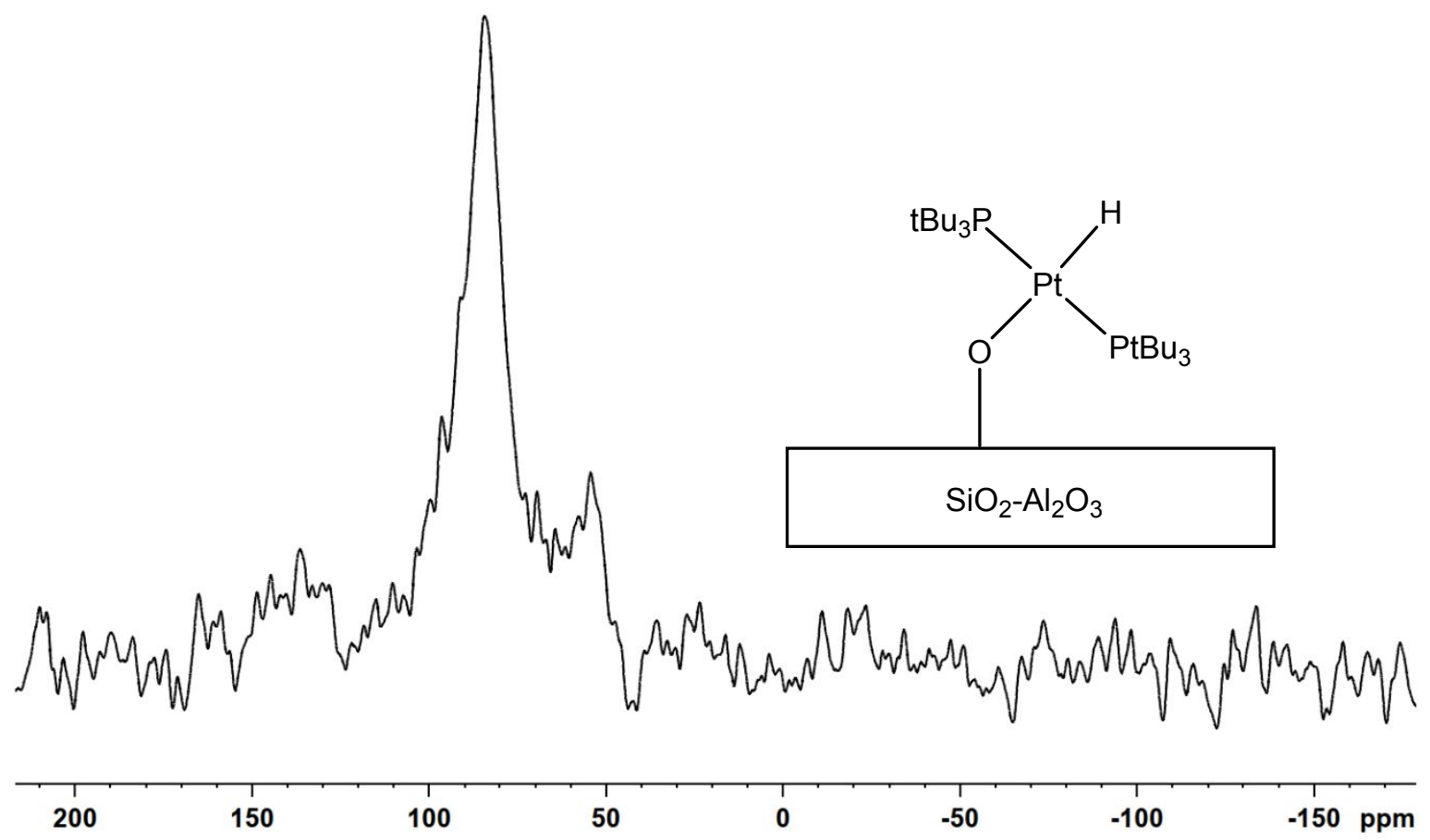

Figure S18. ${ }^{31} \mathrm{P}$ CPMAS NMR spectrum of catalyst $4 \mathrm{c}$. 

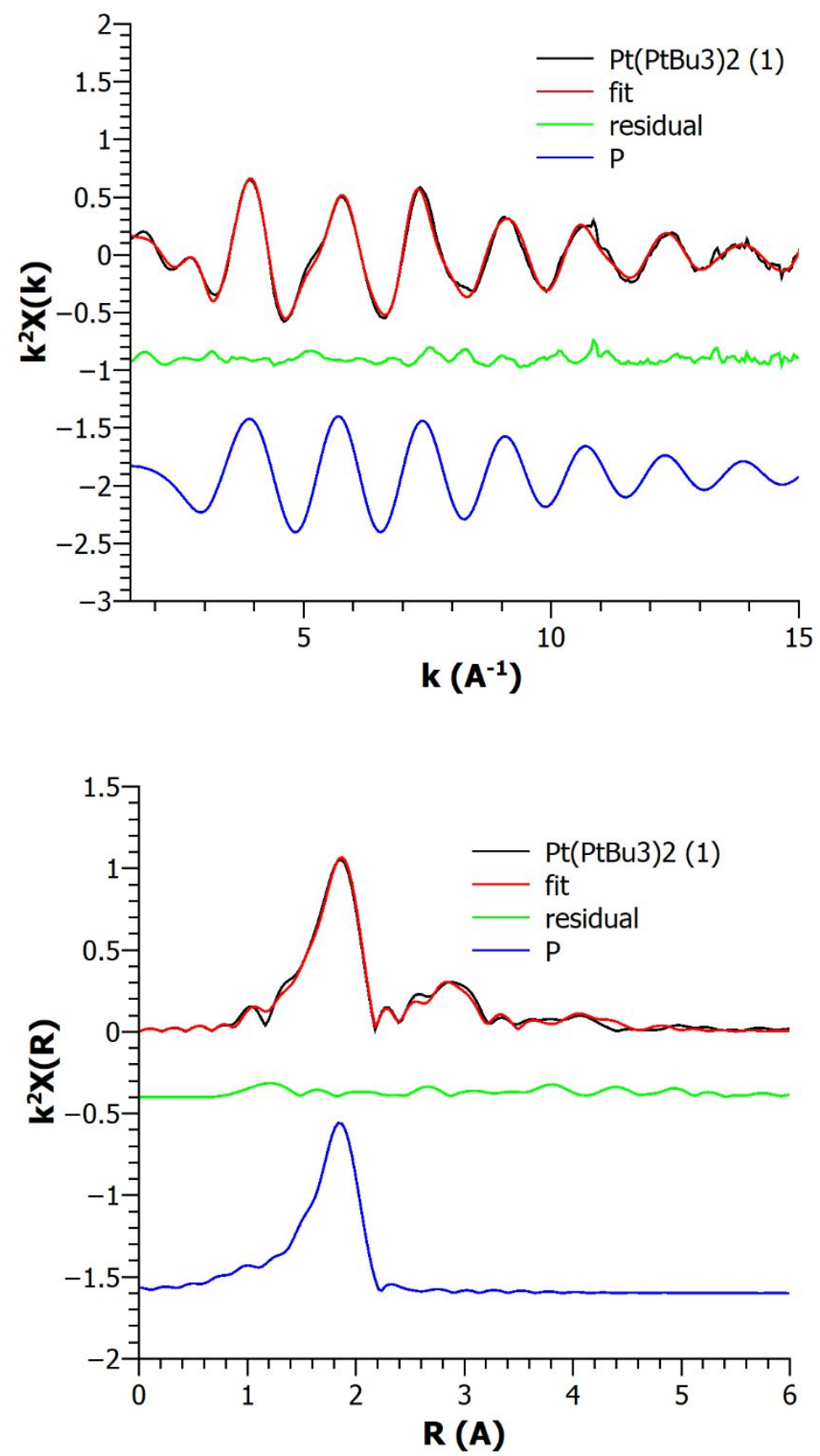

Figure S19. k-space and R-space Pt $\mathrm{L}^{3}$-Edge EXAFS Spectra of 1 with best fit and first coordination sphere. 

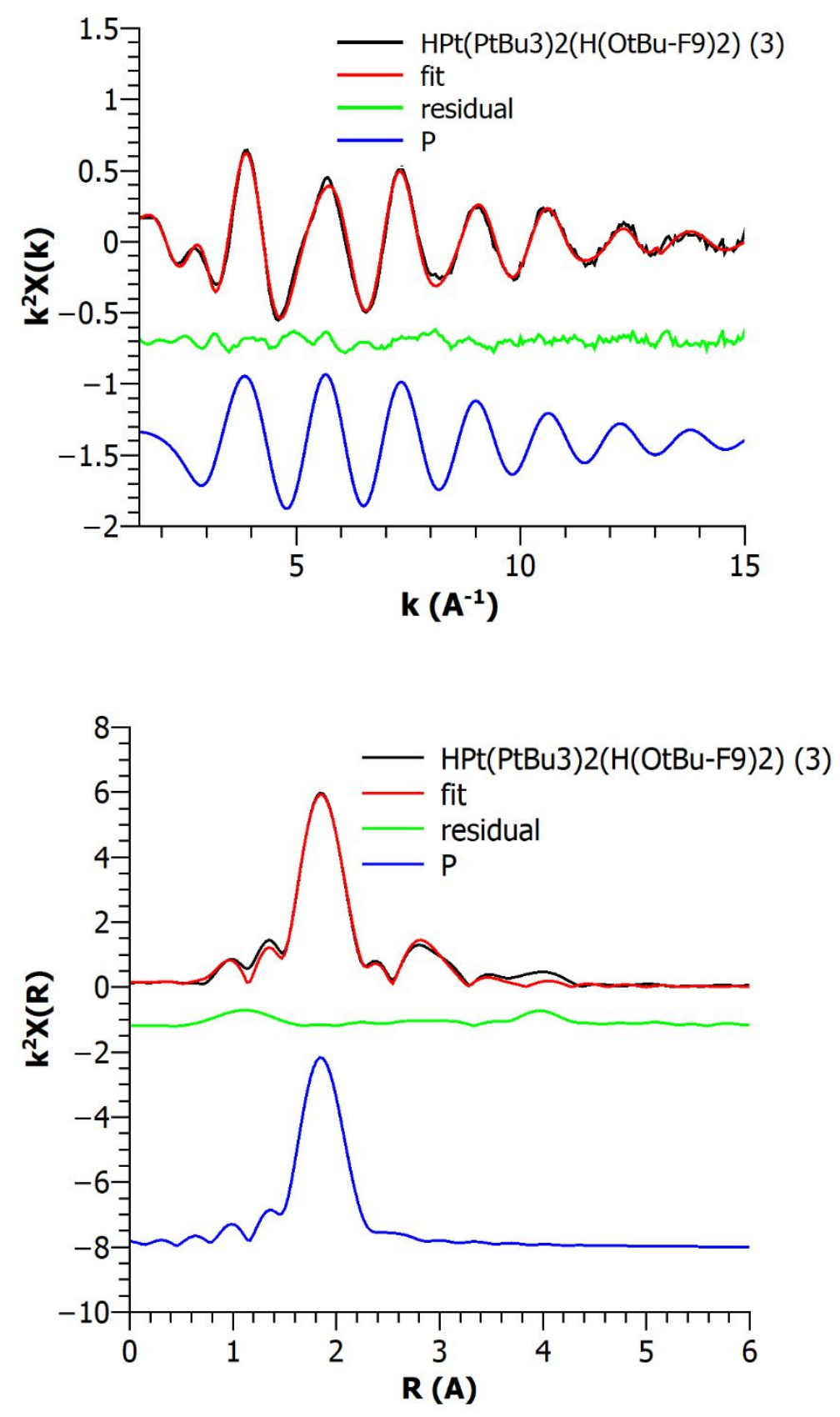

Figure S20. k-space and R-space EXAFS Spectra of $\mathbf{3}$ with best fit. 

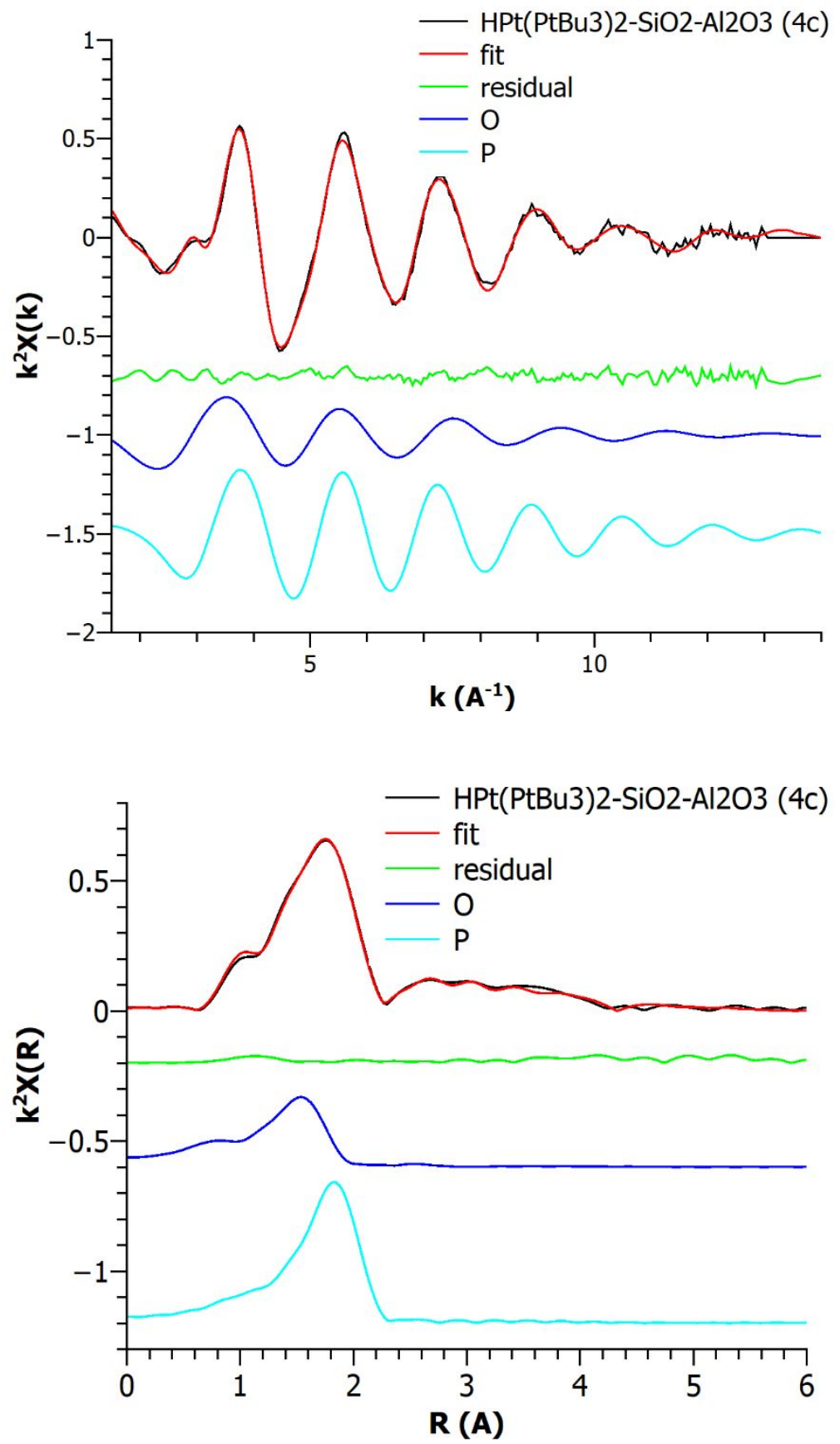

Figure S21. k-space and R-space EXAFS Spectra of 4c with best fit. 


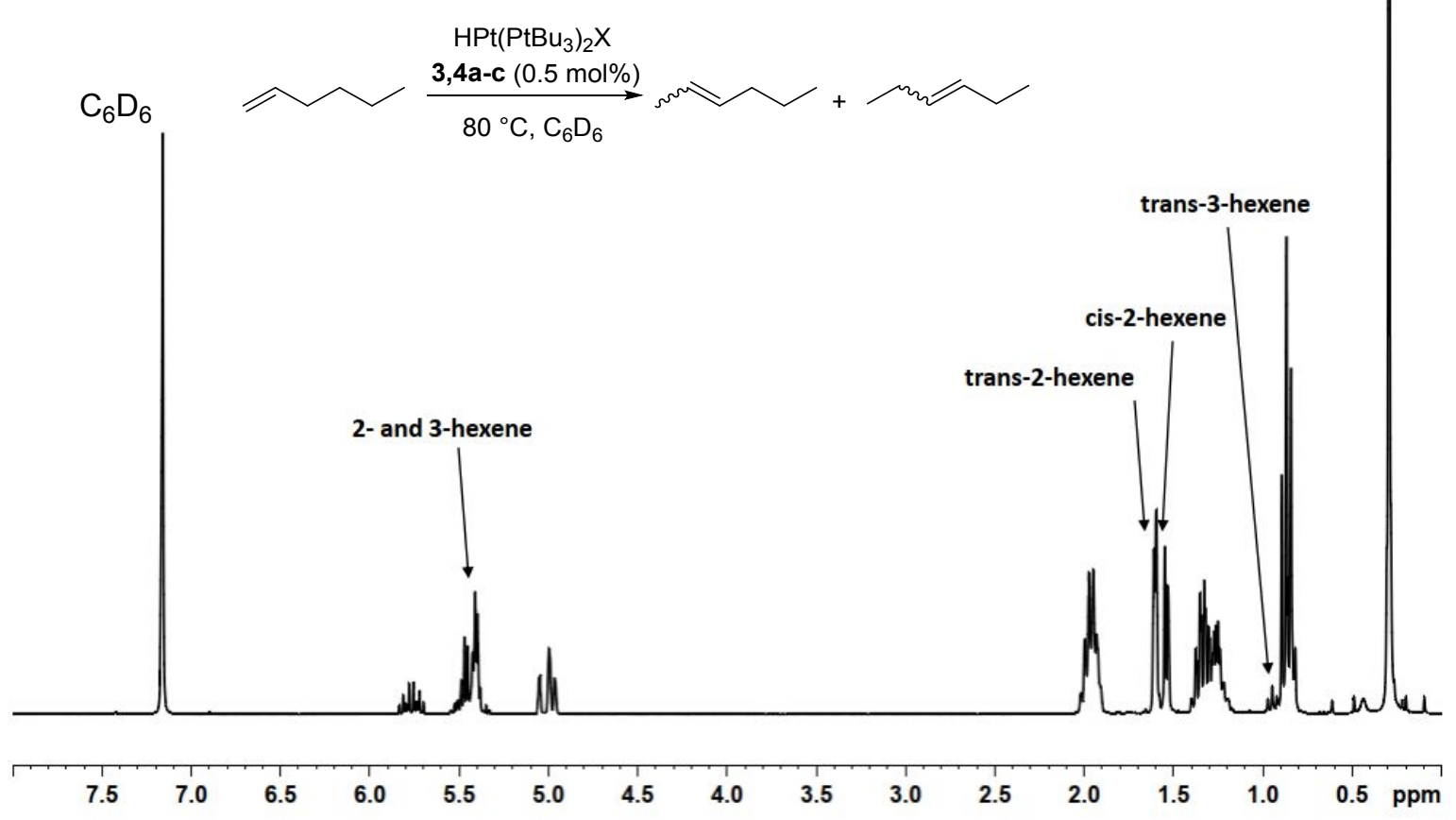

Figure S22. ${ }^{1} \mathrm{H}$ NMR of catalytic isomerization of 1 -hexene by catalyst $\mathbf{4 b}$.

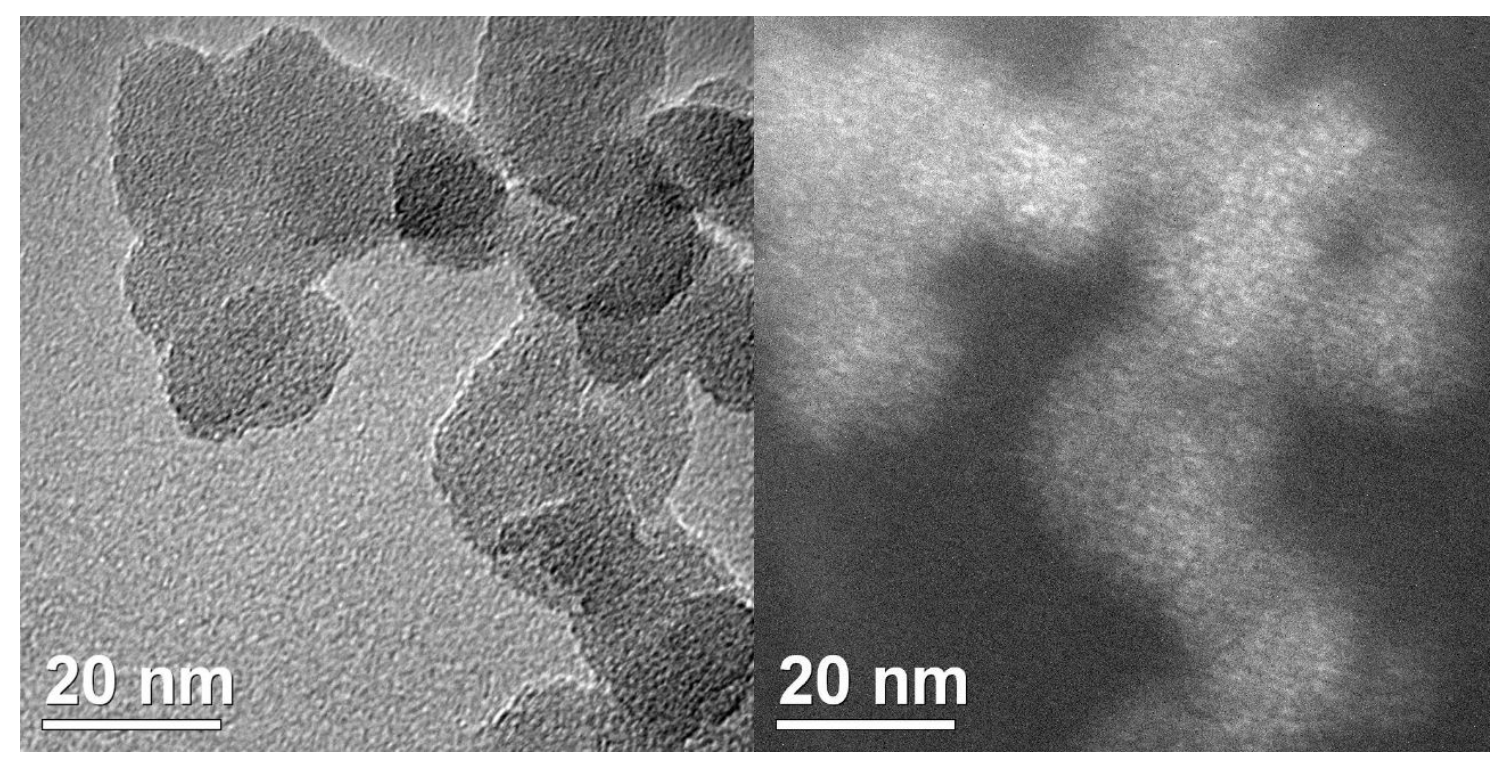

Figure S23. BF (left) and DF (right) TEM of $\mathbf{4 a}$ after isomerization of 1-hexene. 


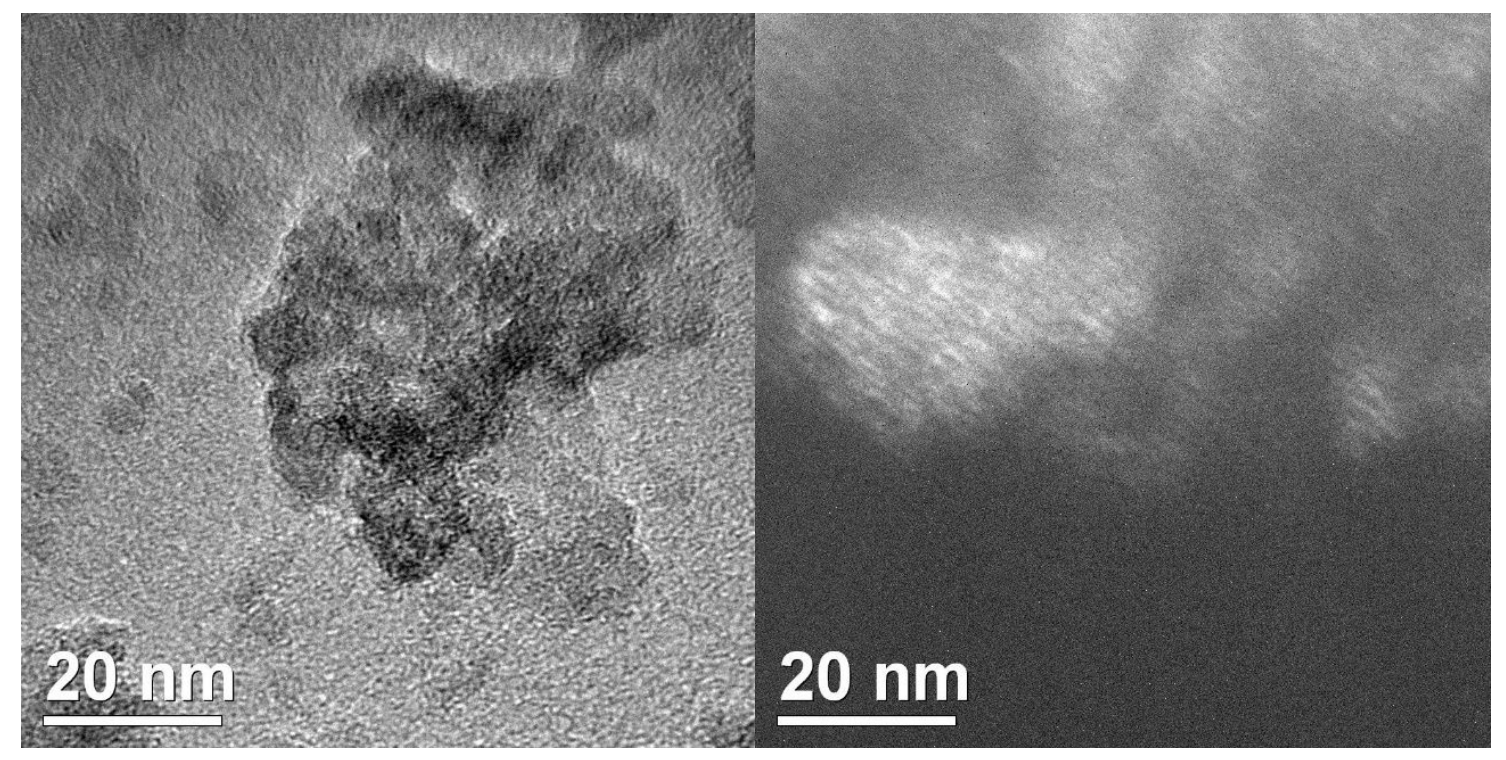

Figure S24. BF (left) and DF (right) TEM of $\mathbf{4 b}$ after isomerization of 1 -hexene.

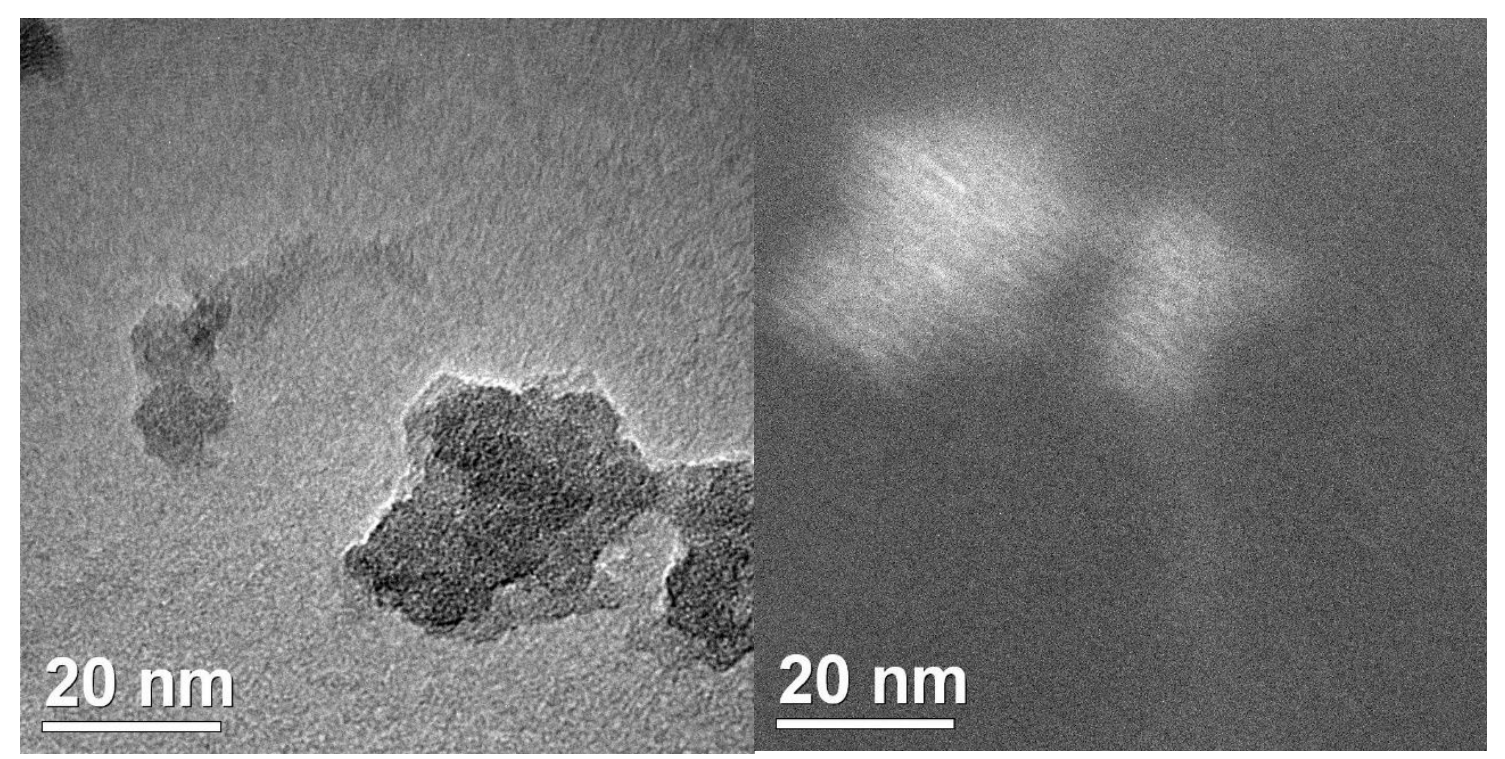

Figure S25. BF (left) and DF (right) TEM of 4c after isomerization of 1-hexene. 


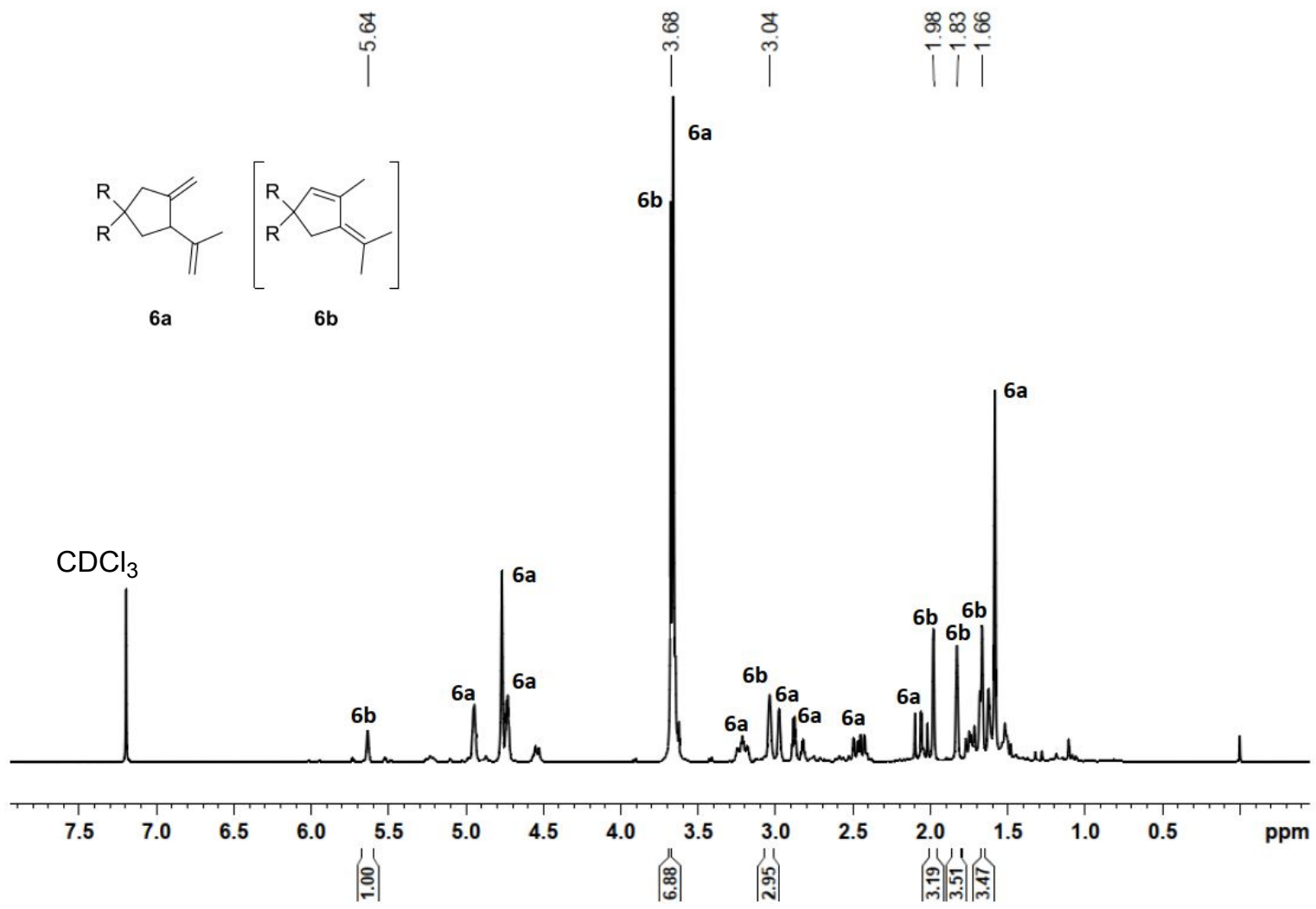

Figure S26. ${ }^{1} \mathrm{H}$ NMR of mixture of $\mathbf{6 a}$ and $\mathbf{6 b}$ after purification by chromatography.

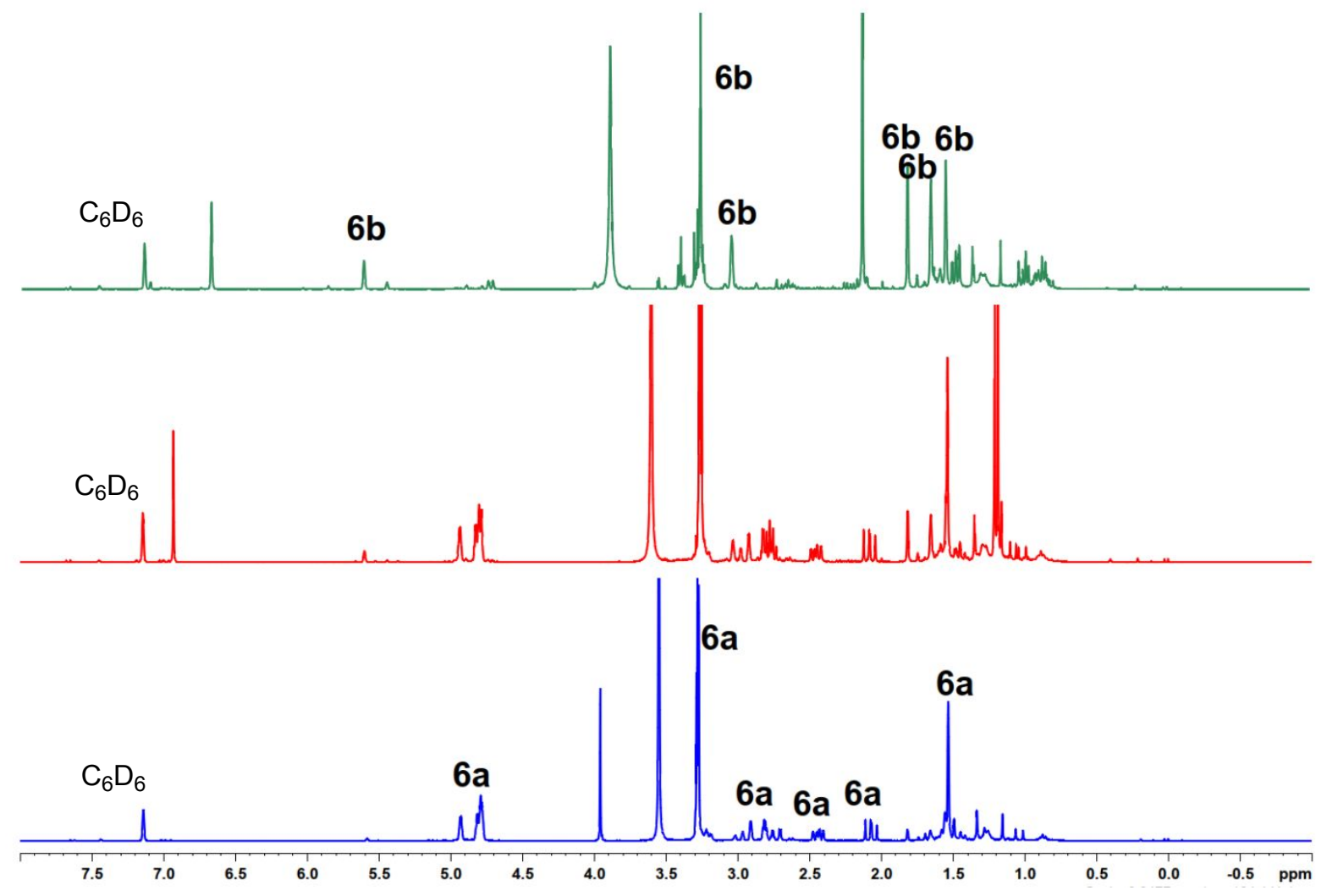

Figure S27. ${ }^{1} \mathrm{H}$ NMR of conversion of 5 to $\mathbf{6 a}+\mathbf{6 b}$ with catalytic 3 after $2 \mathrm{~h}$ (blue), $24 \mathrm{~h}(\mathrm{red})$, and $192 \mathrm{~h}$ (green). The catalyst deactivated at a ratio of 1:3 6a:6b. 


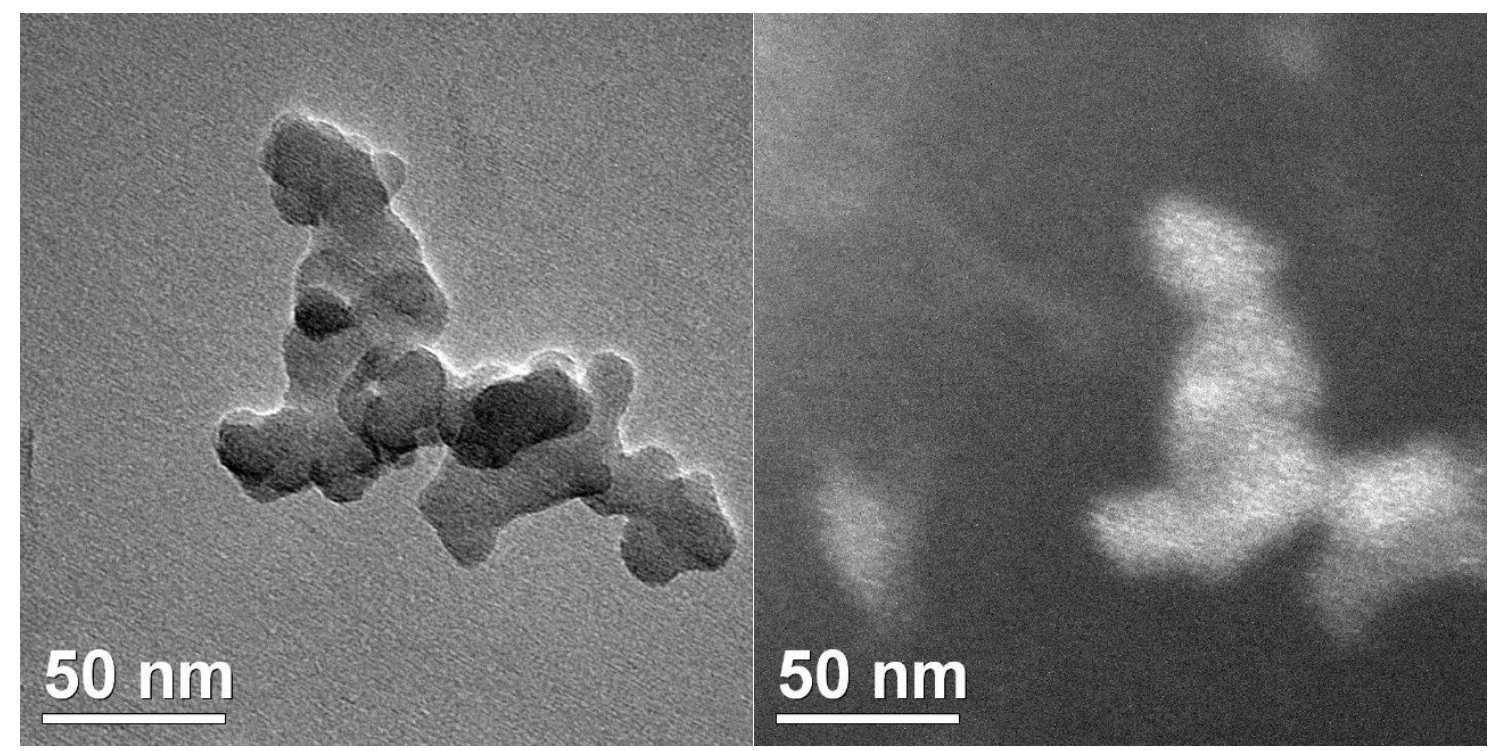

Figure S28. Bright field (left) and dark field (right) TEM of catalyst 4a after isomerization of $\mathbf{5}$. (Sample drift at $20 \mathrm{~nm}$ was too large to DF).

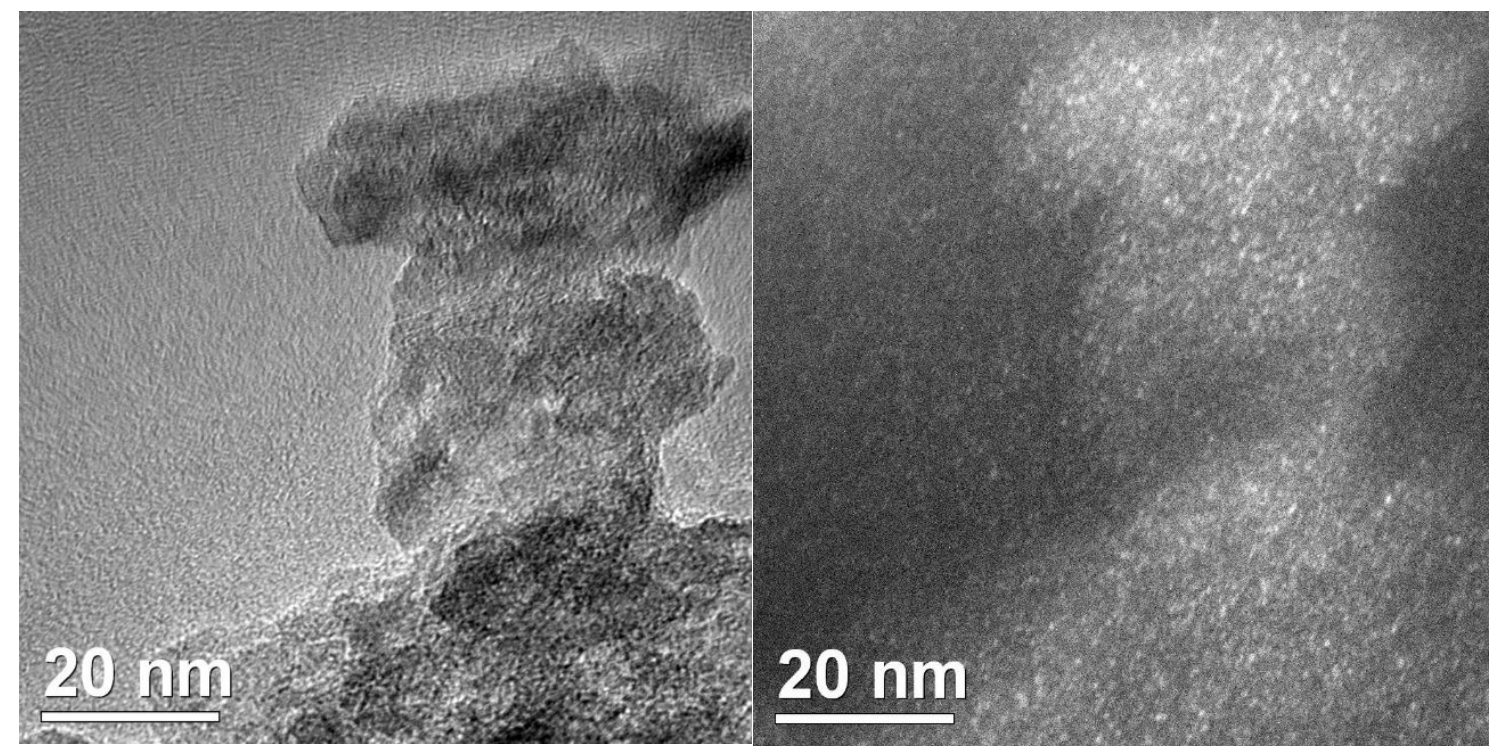

Figure S29. Bright field (left) and dark field (right) TEM of catalyst $\mathbf{4 b}$ after isomerization of 5 . 


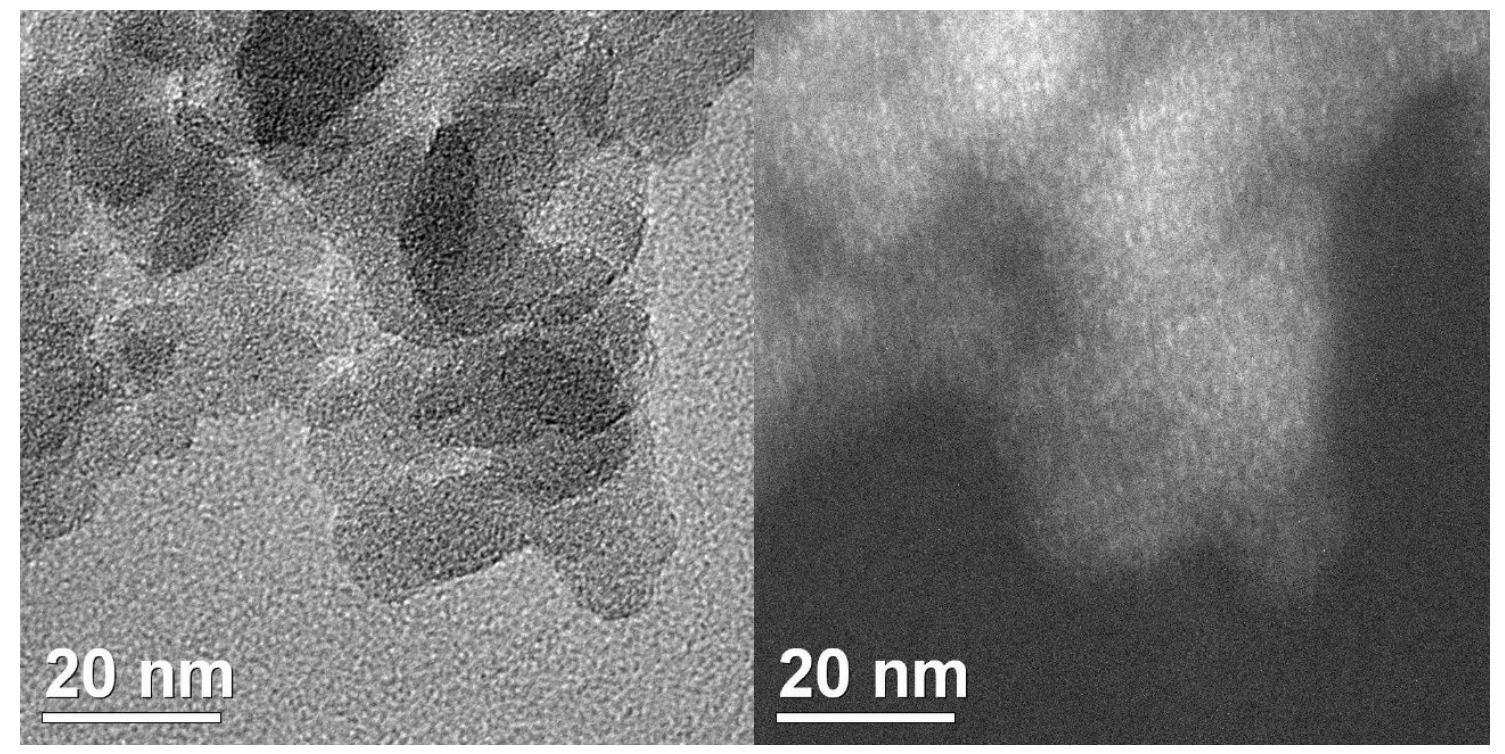

Figure S30. Bright field (left) and dark field (right) TEM of catalyst $4 \mathbf{c}$ after isomerization of $\mathbf{5}$.

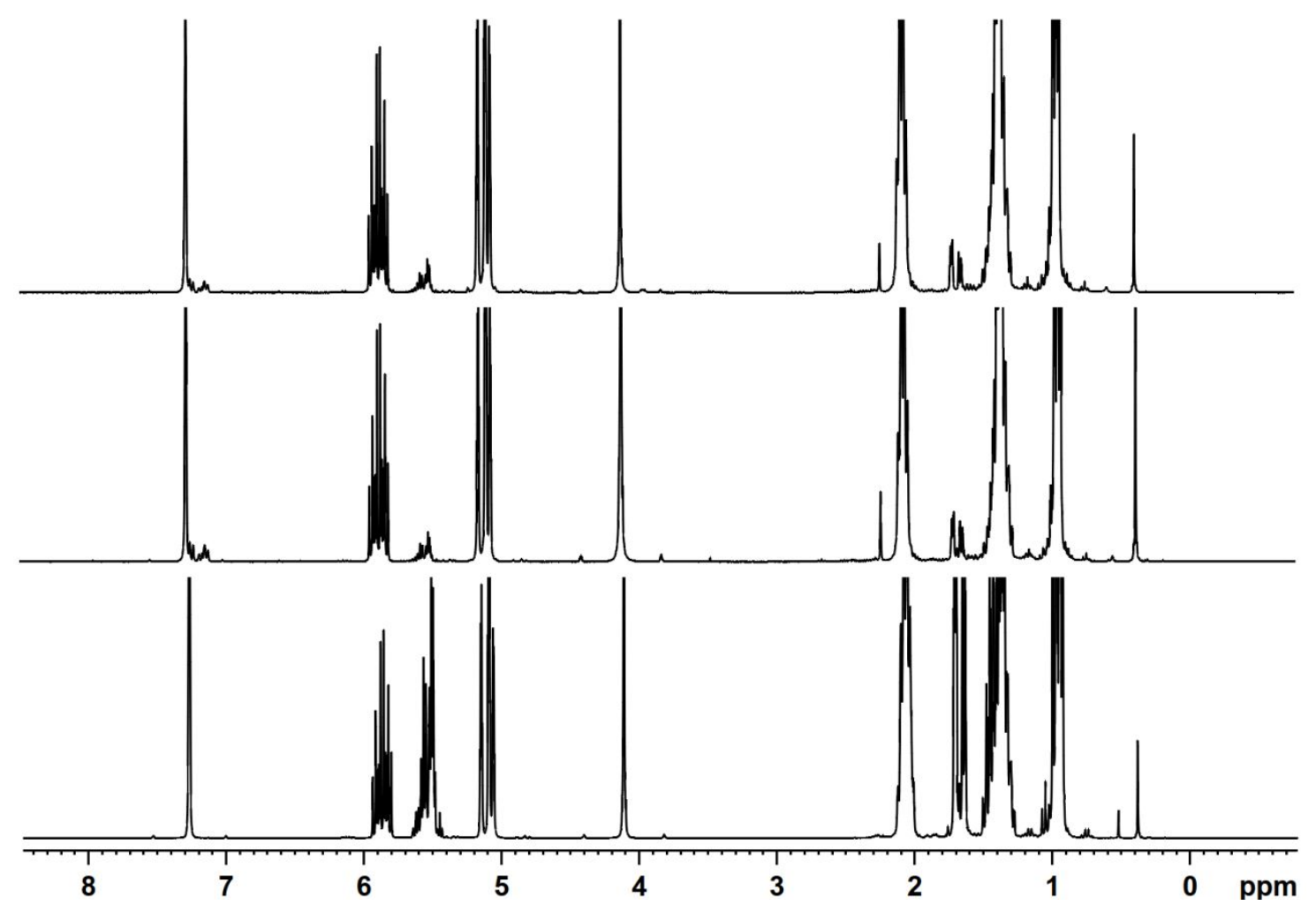

Figure S31. ${ }^{1} \mathrm{H}$ NMR spectra of recycling experiments of $4 b$ for 1 -hexene isomerization (bottom cycle 1 , middle cycle 2 , top cycle 3 ). 


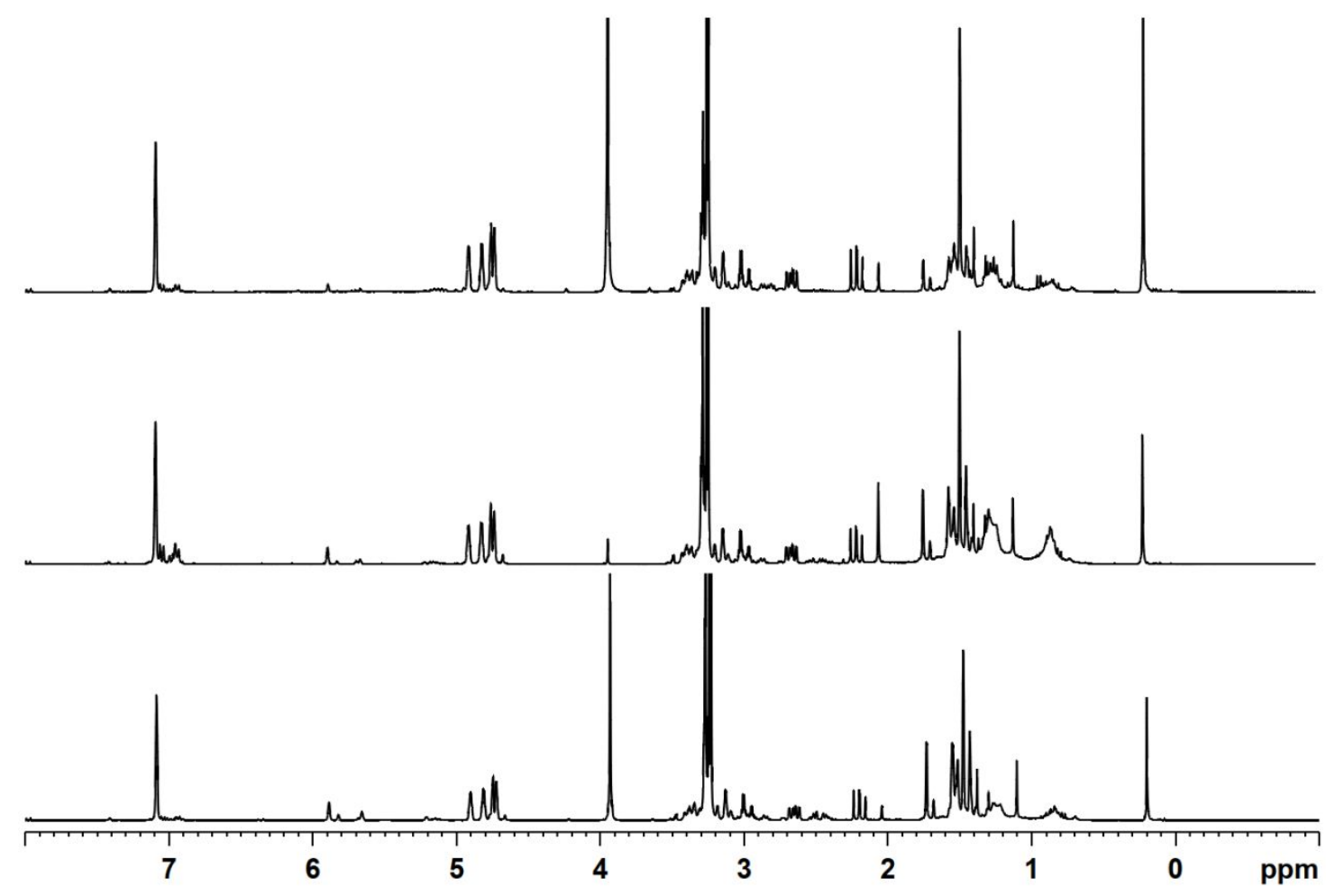

Figure S32. ${ }^{1} \mathrm{H}$ NMR spectra of recycling experiments of $\mathbf{4 c}$ for 5 cycloisomerization (ferrocene as internal standard in $\mathrm{C}_{6} \mathrm{D}_{6}$ ). 